\title{
Spectral attenuation coefficients from measurements of light transmission in bare ice on the Greenland Ice Sheet
}

\author{
Matthew G. Cooper ${ }^{1,2}$, Laurence C. Smith ${ }^{3,4,1}$, Asa K. Rennermalm ${ }^{5}$, Marco Tedesco ${ }^{6,7}$, Rohi Muthyala ${ }^{5}$, \\ Sasha Z. Leidman ${ }^{5}$, Samiah E. Moustafa ${ }^{3}$, and Jessica V. Fayne ${ }^{1}$ \\ ${ }^{1}$ Department of Geography, University of California, Los Angeles, Los Angeles, California, 90027, USA \\ ${ }^{2}$ Pacific Northwest National Laboratory, Richland, Washington, 99354, USA \\ ${ }^{3}$ Institute at Brown for Environment and Society, Brown University, Providence, Rhode Island, 02912, USA \\ ${ }^{4}$ Department of Earth, Environmental and Planetary Sciences, Brown University, Providence, Rhode Island, 02912, USA \\ ${ }^{5}$ Department of Geography, Rutgers, The State University of New Jersey, New Brunswick, New Jersey, 08854, USA \\ ${ }^{6}$ NASA Goddard Institute for Space Studies, New York, New York, 10025, USA \\ ${ }^{7}$ Lamont-Doherty Earth Observatory, Columbia University, New York, New York, 10964, USA
}

Correspondence: Matthew G. Cooper (guycooper@ucla.edu)

Received: 14 February 2020 - Discussion started: 17 March 2020

Revised: 26 February 2021 - Accepted: 1 March 2021 - Published: 21 April 2021

\begin{abstract}
Light transmission into bare glacial ice affects surface energy balance, biophotochemistry, and light detection and ranging (lidar) laser elevation measurements but has not previously been reported for the Greenland Ice Sheet. We present measurements of spectral transmittance at 350$900 \mathrm{~nm}$ in bare glacial ice collected at a field site in the western Greenland ablation zone $\left(67.15^{\circ} \mathrm{N}, 50.02^{\circ} \mathrm{W}\right)$. Empirical irradiance attenuation coefficients at $350-750 \mathrm{~nm}$ are $\sim 0.9$ $8.0 \mathrm{~m}^{-1}$ for ice at $12-124 \mathrm{~cm}$ depth. The absorption minimum is at $\sim 390-397 \mathrm{~nm}$, in agreement with snow transmission measurements in Antarctica and optical mapping of deep ice at the South Pole. From 350-530 nm, our empirical attenuation coefficients are nearly 1 order of magnitude larger than theoretical values for optically pure ice. The estimated absorption coefficient at $400 \mathrm{~nm}$ suggests the ice volume contained a light-absorbing particle concentration equivalent to $\sim 1-2$ parts per billion ( $\mathrm{ppb}$ ) of black carbon, which is similar to pre-industrial values found in remote polar snow. The equivalent mineral dust concentration is $\sim 300-600 \mathrm{ppb}$, which is similar to values for Northern Hemisphere warm periods with low aeolian activity inferred from ice cores. For a layer of quasi-granular white ice (weathering crust) extending from the surface to $\sim 10 \mathrm{~cm}$ depth, attenuation coefficients are 1.5 to 4 times larger than for deeper bubbly ice. Owing to higher attenuation in this layer of near-surface granular ice, optical penetration depth
\end{abstract}

at $532 \mathrm{~nm}$ is $14 \mathrm{~cm}(20 \%)$ lower than asymptotic attenuation lengths for optically pure bubbly ice. In addition to the traditional concept of light scattering on air bubbles, our results imply that the granular near-surface ice microstructure of weathering crust is an important control on radiative transfer in bare ice on the Greenland Ice Sheet ablation zone, and we provide new values of flux attenuation, absorption, and scattering coefficients to support model development and validation.

\section{Introduction}

Understanding the transmission, absorption, and scattering of light in ice is important for snow and ice energy balance modelling (Brandt and Warren, 1993), lidar remote sensing of snow surface elevation and grain size (Deems et al., 2013; Yang et al., 2017), primary productivity beneath sea ice (Frey et al., 2011; Grenfell, 1979), biophotochemistry in ice and snowpack (France et al., 2011), and theoretical predictions of "Snowball Earth" palaeoclimates (Dadic et al., 2013; Warren et al., 2002). Each of these applications requires knowledge of the vertical distribution of light attenuation in ice, which for a medium (such as glacier ice) that both absorbs and scatters light is specified by the spectral attenuation coefficient:

$k_{\mathrm{att}}(\lambda)=k_{\mathrm{abs}}(\lambda)+k_{\mathrm{sca}}(\lambda)$, 
where $k_{\text {abs }}\left(\mathrm{m}^{-1}\right)$ is the absorption coefficient, $k_{\text {sca }}\left(\mathrm{m}^{-1}\right)$ is the scattering coefficient, and all are functions of wavelength $\lambda$. This study reports on the irradiance attenuation coefficient $k_{\text {att }}$ of bare glacier ice in the Greenland Ice Sheet ablation zone, a critical parameter needed to calculate subsurface absorption and scattering of transmitted radiation that to our knowledge has received no direct field study.

Measurements of $k_{\text {att }}$ in snowpack and sea ice indicate three main sources of variation with relevance to geophysical applications. First, the magnitude of $k_{\text {att }}$ is primarily controlled by ice microstructure (e.g. the size, shape, orientation, and number of air bubbles, ice grains, and cracks), via its control on $k_{\text {sca }}$ (Dadic et al., 2013; Libois et al., 2013; Light et al., 2004, 2008). For the range of air bubble sizes $\left(\sim 10^{-3}\right.$ $\left.10^{-4}\right)$ and ice grain sizes $\left(\sim 10^{-1}-10^{-3}\right)$ observed in glacier ice, $k_{\text {sca }}$ is effectively independent of wavelength in the visible and near-infrared spectrum (Bohren, 1983; Dadic et al., 2013; Perovich, 1996). Spectrally, $k_{\text {att }}$ is low in the nearultraviolet and blue-green spectrum $(\sim 250-600 \mathrm{~nm})$, where $k_{\text {abs }}$ is extremely low $\left(<10^{-8}\right)$, and progressively higher for wavelengths $>600 \mathrm{~nm}$, where $k_{\text {abs }}$ rapidly increases up to its maximum value $\left(\sim 10^{-2}\right)$ at the far end of the solar spectrum (Warren and Brandt, 2008). Vertically, $k_{\text {att }}$ is at a maximum at the incident boundary (the snow or ice surface) where a portion of upwelling radiation (i.e. transmitted flux reflected upward) escapes the ice volume before re-reflection downward. Within this near-surface optical boundary layer (Bohren and Barkstrom, 1974), attenuation rates rapidly decrease with depth to an asymptotic value as multiple scattering establishes an isotropic (diffuse) radiation field (Briegleb and Light, 2007; Warren, 1982). For fine-grained dry snow, a few centimetres of depth is typically sufficient to reach the asymptotic regime where monochromatic $k_{\text {att }}$ is constant (Brandt and Warren, 1993). For sea ice the depth required is typically larger and can exceed $>20 \mathrm{~cm}$ depending on nearsurface ice microstructure and the vertical location of the refractive boundary if present (Grenfell, 1991; Grenfell and Maykut, 1977). Attenuation coefficients are also influenced by the horizontal distribution of ice type and surface cover (Frey et al., 2011), but this source of variation is not examined here.

In addition to experimental values obtained from measurements of light transmission in ice or snow, $k_{\text {att }}$ is obtained analytically from optical theory (Bohren, 1987; Warren et al., 2006). Light attenuation in pure ice is specified analytically by the complex refractive index:

$m(\lambda)=m_{\mathrm{re}}(\lambda)-i m_{\mathrm{im}}(\lambda)$,

where $m_{\mathrm{re}}$ is the real part of the complex refractive index ( $\sim 1.31$ in the visible), $m_{\mathrm{im}}$ is the imaginary part, and

$k_{\mathrm{abs}}^{\mathrm{ice}}(\lambda)=\frac{4 \pi}{\lambda} m_{\mathrm{im}}(\lambda)$

is the absorption coefficient of pure ice (Warren et al., 2006; Warren and Brandt, 2008).
Light attenuation in glacier ice differs from pure ice owing to compositional and structural factors that control scattering and absorption, such as the size, geometry, and vertical distribution of embedded light-absorbing particles (LAPs) and light-scattering air bubbles and ice grains of size larger than wavelength (Askebjer et al., 1997; Picard et al., 2016; Price and Bergström, 1997b; Warren et al., 2006). Analytical methods typically approximate ice and snowpack as homogeneous plane-parallel slabs of spheres having the same volume-to-surface-area ratio (i.e. optically equivalent grain size) as the collection of non-spherical ice grains and air bubbles in realistic ice (Brandt and Warren, 1993; Grenfell and Warren, 1999; Wiscombe and Warren, 1980). Mie theory is used to calculate the single-scattering properties, and twostream radiative transfer approximations are used to calculate multiple scattering and bulk absorption in the ice volume (Bohren and Barkstrom, 1974; Mullen and Warren, 1988; Wiscombe and Warren, 1980). The single-scattering properties can also be derived from the ratio of surface area to mass (i.e. specific surface area) with or without the assumption of spherical scattering geometry (Kokhanovsky and Zege, 2004; Malinka, 2014), as applied to the highly scattering granular surface layer on sea ice (Malinka et al., 2016). Models of the prior form have been used to calculate subsurface meltwater production caused by penetration of solar radiation in ice in both Greenland (van den Broeke et al., 2008; Kuipers Munneke et al., 2009) and Antarctica (Brandt and Warren, 1993; Hoffman et al., 2014; Liston et al., 1999a, b; Liston and Winther, 2005). However, theoretical values for $k_{\text {att }}$ are rarely validated experimentally, and to our knowledge no such experimental values exist for near-surface glacier ice.

In addition to ice surface energy balance, understanding light attenuation in ice is important for interpreting interactions between visible-wavelength light sources and ice surfaces, for example laser altimetry measurements of ice surface elevation (Deems et al., 2013; Gardner et al., 2015; Greeley et al., 2017). The reciprocal of $k_{\text {att }}$ is the attenuation length, or the average distance travelled by a photon before attenuation by absorption or scattering (Ackermann et al., 2006). In the context of altimetry, the attenuation length is sometimes referred to as the penetration depth, or the average depth to which the electromagnetic signal penetrates before it is backscattered to the atmosphere (Ridley and Partington, 1988; Rignot et al., 2001; Zebker and Weber Hoen, 2000). The laser altimeter onboard Ice, Cloud, and Land Elevation Satellite (ICESat) transmitted $1064 \mathrm{~nm}$ laser pulses to measure the distance (range) between the satellite and ice sheet surfaces (Schutz et al., 2005). Photons with a wavelength of $1064 \mathrm{~nm}$ penetrate into snowpack no more than a few centimetres (Brandt and Warren, 1993; Järvinen and Leppäranta, 2013). This length scale is smaller than typical laser altimetry surface elevation errors due to ice and snow surface roughness and geolocation uncertainty (Deems et al., 2013). In contrast, the laser altimeter onboard ICESat2 transmits $532 \mathrm{~nm}$ laser pulses (Markus et al., 2017). Ice 
is $\sim 10$ times more transparent at $532 \mathrm{~nm}$ than at $1064 \mathrm{~nm}$ (Warren and Brandt, 2008), and photons at $532 \mathrm{~nm}$ may penetrate many tens of centimetres into glacier ice. These subsurface scattered photons may introduce a range bias in ICESat2 surface elevation retrievals over glacier ice, similarly to radar penetration into snow (Brunt et al., 2016; Gardner et al., 2015; Greeley et al., 2017; Smith et al., 2018). To our knowledge no in situ observations of $532 \mathrm{~nm}$ optical penetration depth for bare glacier ice exist, precluding field validation of penetration depth obtained from theoretical radiative transfer models.

The purpose of this investigation is to provide experimental values for $k_{\text {att }}$ obtained from measurements of solar flux attenuation in bare ice in the Greenland Ice Sheet ablation zone and to compare them with theoretical values for $k_{\text {att }}$ obtained from the two-stream analytical solution (see Eq. 26 in Bohren, 1987; Schuster, 1905). We benchmark our field estimates against the two-stream solution because of its wide use in surface energy balance models applied to snow and ice. In Sect. 2 we describe the field measurements and the optical theory used to interpret the solar flux attenuation. In Sect. 3 we report values for $k_{\text {att }}$ obtained from our measurements, compare them with values obtained from two-stream theory, and propose a simple empirical model that accounts for enhanced near-surface attenuation. In Sect. 4 we discuss measurement uncertainty, and in Sect. 5 we discuss how our $k_{\text {att }}$ values differ from prior experimental values acquired in sea ice, snowpack, and deep South Pole glacial ice and the implication of these differences for modelling radiative transfer in bare glacier ice. To demonstrate the broader implications of our study, we suggest how our findings can be used to improve models for subsurface heating of ablating glacier ice.

\section{Methods}

\subsection{Transmittance measurements}

Ice transmittance was measured on 20 and 21 July 2018 in the Kangerlussuaq sector of the western Greenland Ice Sheet. The study site is located $\sim 1 \mathrm{~km}$ from the ice sheet margin at $840 \mathrm{~m}$ above sea level. $\left(67.15^{\circ} \mathrm{N}, 50.02^{\circ} \mathrm{W}\right)$. Subsurface (inice) spectral irradiance was measured at a $\sim 0.35 \mathrm{~nm}$ spectral resolution in the wavelength range of $350-900 \mathrm{~nm}$ with an Ocean Optics ${ }^{\circledR}$ JAZ spectrometer. Light was guided from the ice interior to the spectrometer with a $3 \mathrm{~mm}$ diameter Kevlar-sheathed fibre-optic cable fitted inside a $2 \mathrm{~m}$ long insulated white PVC tube (Fig. 1). The fibre was attached at one end to an irradiance sensor consisting of a $90^{\circ}$ collimating lens adapter and a remote cosine receptor (RCR) with a Spectralon ${ }^{\circledR}$ diffusing element. The RCR lens barrel was wrapped in white PTFE tape and set $2 \mathrm{~mm}$ out from the PVC tube exterior to act as a contact horizon between its diffusing element and the ice. The system was operated from a battery- powered computer running the Ocean Optics ${ }^{\circledR}$ OceanView software placed on a tripod platform oriented $180^{\circ}$ away from the sun and at a $2.5 \mathrm{~m}$ horizontal distance from the measurement location.

To access the interior of the ice, holes were drilled horizontally into a $2 \mathrm{~m}$ high sidewall of a natural ice feature with a battery-powered hand drill fitted with a $3 \mathrm{~cm}$ diameter Kovacs auger bit. To drill these holes, the auger was advanced into the sidewall approximately $20 \mathrm{~cm}$ and levelled horizontally with a digital spirit level, and the sequence was repeated to a $2 \mathrm{~m}$ horizontal depth. The PVC tube-fibre-optic assembly was then inserted into the hole, RCR facing upward, and a $2 \mathrm{~m}$ long ruler was shimmed under the bottom of the PVC tube to ensure the RCR barrel preserved contact with the overlying ice thus minimizing stray light contamination into the RCR field of view. Ice shavings were packed around the drill hole to prevent light reflection into the hole. Spectral irradiance was measured using a 20 -scan average with a $0.0228 \mathrm{~s}$ integration time per scan, yielding a $0.46 \mathrm{~s}$ total integration time per irradiance measurement. Irradiance measurements were recorded at a $1 \mathrm{~Hz}$ frequency for $30 \mathrm{~s}$ yielding 30 irradiance profiles at each depth, after which the tube was removed; the next hole was drilled, and the sequence was repeated, working from the top hole toward the bottom on 20 July and from the bottom hole toward the top on 21 July. The measurements were completed between 13:45 and 14:35 local time (UTC-3) on 20 July and between 13:09 and 14:00 on 21 July, at solar zenith angles of $\sim 48-51^{\circ}$. Solar noon at this time and location is $\sim 13: 26$.

Background upwelling and downwelling spectral irradiances were measured continuously at $2 \mathrm{~m}$ height above the ice surface $\sim 3 \mathrm{~m}$ away from the in-ice measurements with a dual-channel Ocean Optics JAZ spectrometer. These data were recorded at a 1 min frequency using a 30-scan average with a $0.011 \mathrm{~s}$ integration time. Light was guided to the spectrometer via two $3 \mathrm{~m}$ fibre-optic cables attached to two RCRs mounted in an upward-looking and downward-looking orientation on a $2 \mathrm{~m}$ long horizontally levelled boom attached to a vertical mast frozen into the ice. The horizontal boom became unstable on 21 July, and the upward-looking RCR was moved to the vertical mast; the downward-looking RCR was decommissioned.

The surface-based spectrometer was calibrated for absolute irradiance in a controlled setting prior to the field experiment using an Ocean Optics HL-3P radiometrically calibrated halogen light source. During the field experiment, the in-ice spectrometer was cross-calibrated to the surface spectrometer by holding it level above the ice surface in an upward-looking orientation $\sim 3 \mathrm{~m}$ away from the surface spectrometer. Cross-calibration irradiance profiles were collected on 20 and 21 July immediately prior to subsequent inice measurements. All in-ice irradiances are cross-calibrated to the surface spectrometer as a pre-processing step prior to further analysis. 


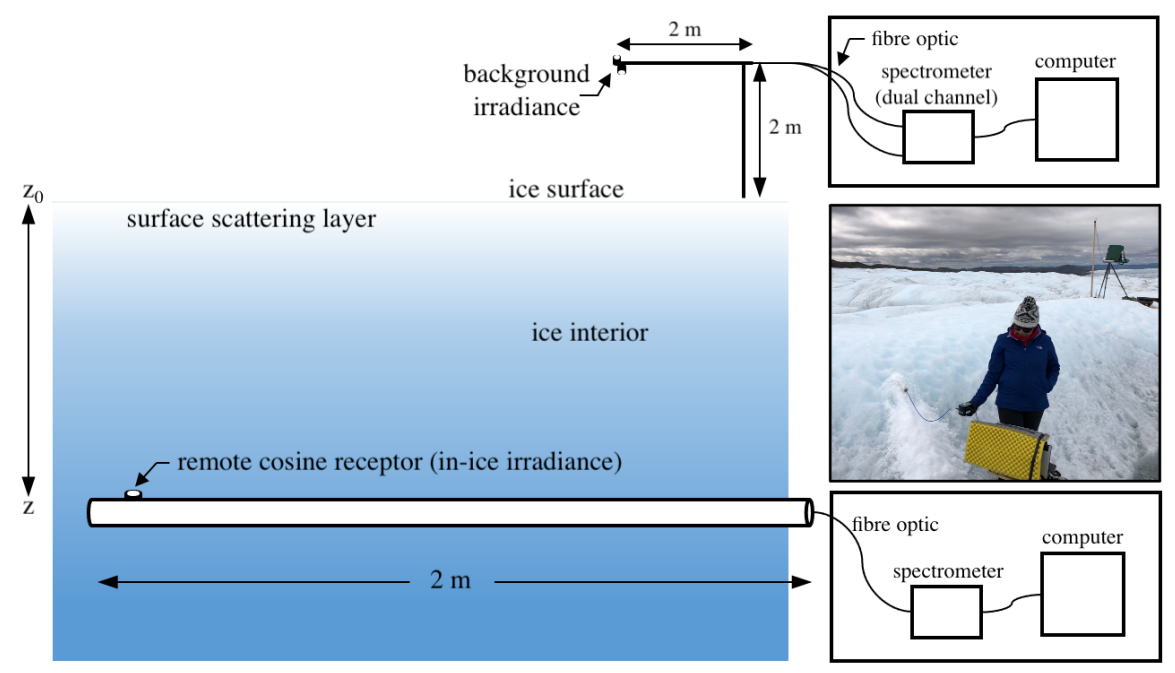

Figure 1. The irradiance sensor is comprised of a remote cosine receptor and fibre-optic light guide fitted inside an insulated white PVC tube of $2 \mathrm{~m}$ in length. Holes are drilled level and horizontal into the ice; the tube is inserted, and drill shavings are packed around the hole to prevent stray reflections. The cosine receptor collects the downwelling light and guides it to the fibre-optic cable that transmits the light to an Ocean Optics ${ }^{\circledR}$ JAZ spectrometer, and a computer running the Ocean Optics ${ }^{\circledR}$ OceanView software records the spectra. Background downwelling surface spectra are recorded on a $2 \mathrm{~m}$ mast drilled into the ice approximately $3 \mathrm{~m}$ to the northwest of the in-ice measurement location (see photo background). This photograph was taken on 21 July 2018 at 13:22 local time (UTC-3).

Dark-current spectra were recorded prior to each irradiance measurement as input to the OceanView automated dark-current correction module. To measure dark current, the RCR lens barrel was capped with a custom-fit opaque metal cap provided by Ocean Optics. OceanView adjusts these spectra in real time for changes in integration time and for charge leakage if detected, corrects the nonlinear analogueto-digital response of the linear silicon charge coupled device, and applies a boxcar smoothing over adjacent pixels to further reduce noise. Following these automated corrections, the opaque cap was left in place and residual dark current (noise) was recorded with the reference spectrometer in its experimental setup as described above and with the in-ice spectrometer held level above the ice surface in an upwardlooking orientation. These residual dark-current spectra are treated as systematic errors and are subtracted from all irradiance profiles as a pre-processing step prior to analysis (Fig. 2a).

\subsection{Weather conditions}

The 20 July experiment was conducted under low, thick cloud cover with light rain and no direct sun, ideal conditions for estimating the attenuation of diffuse light in ice. The 21 July experiment was conducted under higher, thinner cloud cover with no rain and very brief periods of intermittent direct sun (see Fig. 1). The effect of intermittent direct sun was easily identified in the in-ice irradiance measurements as a rapid increase in light intensity, which only occurred during the third measurement on 21 July. This was mitigated by averaging over the first 10 in-ice irradiance profiles for that measurement, prior to the rapid increase in light intensity, and discarding the remainder.

\subsection{Ice thickness and density}

The ice thickness between detector positions was measured to the nearest millimetre with a metre stick and converted to units of solid ice thickness with the relation

$\Delta z=\Delta h \frac{\rho}{\rho_{\text {ice }}}$,

where $\Delta h$ is in situ ice thickness between detector positions, $\rho$ is in situ ice density, $\rho_{\text {ice }}$ is solid ice density $\left(917 \mathrm{~kg} \mathrm{~m}^{-3}\right)$, and $\Delta z$ is solid ice thickness between detector positions. Two separate observers made 10 independent measurements of $\Delta h$. In addition, one observer made 41 replicate measurements of an ablation stake using the same metre stick, yielding a mean difference and standard error in $\Delta h$. The ice density $\rho$ was measured on a $1.2 \mathrm{~m}$ ice core extracted at the measurement location with a Kovacs Mark IV corer (https:// kovacsicedrillingequipment.com/, last access: 7 April 2021) (Fig. 3). The ice core was split along natural breaks into three segments that were measured to the nearest millimetre with a calliper and weighed to the nearest gram on an Acculab digital scale. 

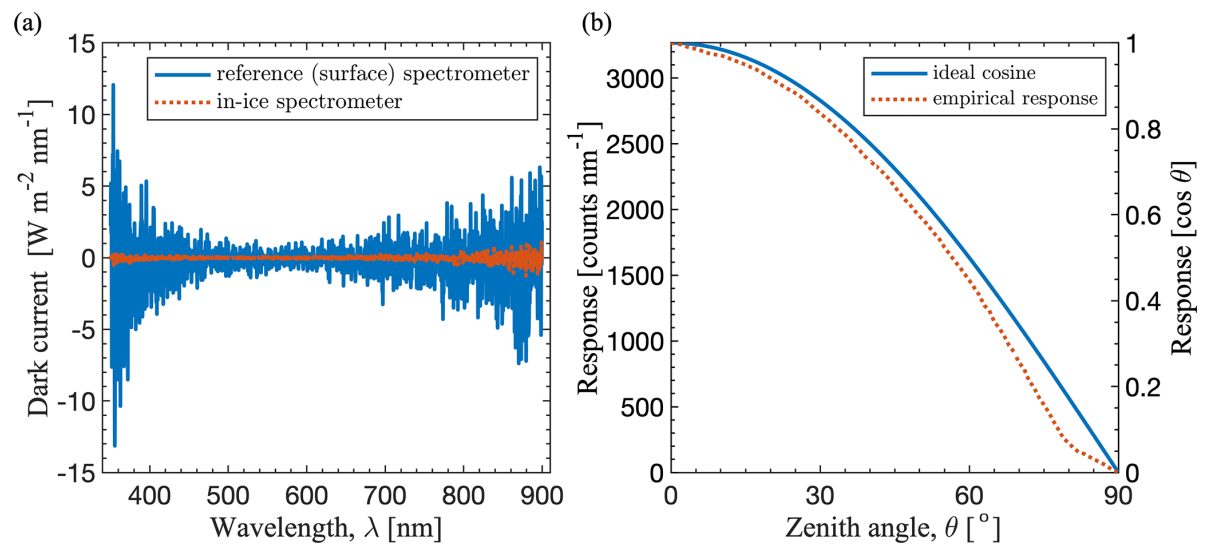

Figure 2. (a) Residual dark-current spectra for the surface-based reference spectrometer and the in-ice spectrometer. Dark-current spectra are recorded prior to each absolute irradiance measurement as input to the OceanView software dark-current correction module. Shown here are residual dark-current spectra after automated software correction, which are treated as systematic errors and subtracted from irradiance profiles prior to fitting experimental $k_{\text {att }}$ values. (b) Ideal angular response function (ideal cosine) and empirical angular response function provided by Ocean Optics from laboratory measurements on the same type of irradiance sensor used in this study. The dashed red line in (b) is used as an empirical probability density function for the angular response of the cosine receptor in our Monte Carlo simulations of detector interference.
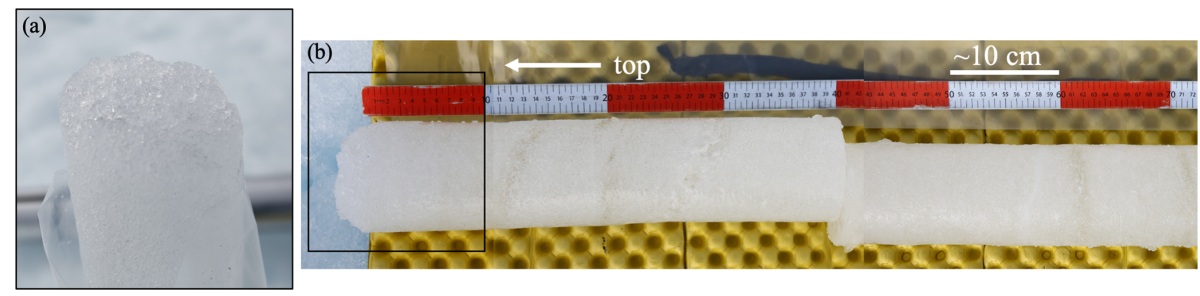

Figure 3. Photographs of an ice core collected at the field site. (a) The upper few centimetres of ice is semi-granular, with $\sim 4 \mathrm{~cm}$ of unrecovered granular ice not shown. (b) The $122 \mathrm{~cm}$ ice core was broken into three segments corresponding to depths of 4-45, 45-74, and $74-122 \mathrm{~cm}$ below the ice surface (the far right of the image in $\mathbf{b}$ is at $74 \mathrm{~cm}$ ). The density of these segments is 801,884 , and $888 \mathrm{~kg} \mathrm{~m}^{-3}$, respectively. Below $\sim 10 \mathrm{~cm}$, the bubbly ice appears foliated, indicating variations in bubble density and size distribution that affect scattering. Black box in (b) is approximately the image area in (a).

\subsection{Experimental asymptotic flux attenuation coefficients and ice surface albedo}

Spectral asymptotic flux attenuation coefficients are estimated by fitting a Bouguer-law exponential decay model to the in-ice irradiance profiles (Grenfell and Maykut, 1977):

$$
I_{z}(\lambda)=I_{0}(\lambda) \exp \left[-k_{\text {att }}(\lambda)\left(z-z_{0}\right)\right]
$$

where $k_{\text {att }}(\lambda)$ is the asymptotic flux attenuation coefficient, $I_{z}(\lambda)$ is in-ice spectral irradiance at depth $z, I_{0}(\lambda)$ is background downwelling spectral irradiance, $z_{0}$ is the ice surface, and

$T_{z}(\lambda)=I_{z}(\lambda) / I_{0}(\lambda)$

is spectral transmittance. The optical depth $\tau_{z}(\lambda)$ is a dimensionless path length that scales the physical thickness of a layer by its attenuation rate:

$\tau_{z}(\lambda)=-\ln T_{z}(\lambda)=k_{\text {att }}(\lambda)\left(z-z_{0}\right)$.
Estimates of $k_{\text {att }}(\lambda)$ for each spectral band are obtained by solving a linear equation of the form

$\tau_{z}(\lambda)=\tau_{0}(\lambda)+k_{\mathrm{att}}(\lambda)\left(\Delta z+\varepsilon_{\Delta z}\right)+\varepsilon_{\Delta \tau}$,

where $\tau_{0}$ is a parameter ( $y$ intercept), $\Delta z=z-z_{0}$ is ice thickness, $\varepsilon_{\Delta z}$ is an error term that represents ice thickness measurement uncertainty, and $\varepsilon_{\Delta \tau}$ is an error term that represents optical path measurement uncertainty. Equation (8) is solved by maximum likelihood estimation (MLE), which gives an unbiased estimate of the slope when measurement errors are present in both the independent and the dependent variables (see Sect. 2.9) (York et al., 2004).

The attenuation length $l_{\text {att }}(\lambda)$ is the inverse of $k_{\text {att }}(\lambda)$ and is analogous to the photon mean free path or transport length (Ackermann et al., 2006). It is equivalent to the path length in ice required to attenuate irradiance to $37 \%(1 / e)$ of its incident intensity, i.e. the path length at which $T=1 / e$ and 
$\tau=1$ :

$l_{\text {att }}(\lambda)=\frac{1}{k_{\text {att }}(\lambda)}$.

The ice surface spectral albedo is the ratio of the upwelling spectral irradiance to the downwelling spectral irradiance:

$\alpha(\lambda)=\frac{I \uparrow(\lambda)}{I \downarrow(\lambda)}$,

and the broadband albedo is

$\alpha=\int_{\lambda_{1}}^{\lambda_{2}} \alpha(\lambda) I_{0}(\lambda) \mathrm{d} \lambda / \int_{\lambda_{1}}^{\lambda_{2}} I_{0}(\lambda) \mathrm{d} \lambda$.

\subsection{Asymptotic flux attenuation coefficients}

Theoretical $k_{\text {att }}(\lambda)$ values are calculated using the asymptotic solution to the $\delta$-Eddington two-stream radiative transfer approximation (Joseph et al., 1976; Schuster, 1905):

$k_{\mathrm{att}}(\lambda)=\frac{3}{4} \frac{Q_{\mathrm{ext}}(\lambda)}{r_{\mathrm{eff}}} \sqrt{3(1-\bar{\omega}(\lambda))(1-g(\lambda) \bar{\omega}(\lambda))}$,

where $Q_{\text {ext }}(\lambda)$ is the extinction efficiency; $r_{\text {eff }}$ is the effective scattering particle radius $(\mathrm{m}) ; g(\lambda)$ is the average cosine of the scattering angle, also referred to as the asymmetry parameter; and $\bar{\omega}(\lambda)$ is the single-scattering albedo,

$\bar{\omega}(\lambda)=\frac{\sigma_{\mathrm{sca}}(\lambda)}{\sigma_{\mathrm{att}}(\lambda)}$,

where $\sigma_{\text {att }}(\lambda)$ and $\sigma_{\text {sca }}(\lambda)$ are the single-scattering attenuation coefficient $\left(\mathrm{m}^{-1}\right)$ and scattering coefficient $\left(\mathrm{m}^{-1}\right)$, respectively. Equation (12) describes light attenuation by multiple scattering and absorption in a homogeneous planeparallel slab of absorbing spheres far from any boundaries (Bohren, 1987).

To estimate $r_{\text {eff }}$, Eq. (12) is inverted and solved by iteration for the value of $r_{\text {eff }}$ that minimizes the difference between measured and calculated $k_{\text {att }}$ at $\lambda=600 \mathrm{~nm}$. This method assumes that all absorption at $600 \mathrm{~nm}$ is due to ice (Warren et al., 2006). If absorption was influenced by LAPs, $r_{\text {eff }}$ would be overestimated. Values for $Q_{\text {ext }}(\lambda), g(\lambda)$, and $\bar{\omega}(\lambda)$ are obtained from Mie scattering algorithms provided as MATLAB $^{\circledR}$ code (Mätzler, 2002) with input $m(\lambda)$ from Warren and Brandt (2008). The Mie solutions at each wavelength are integrated over a Gaussian size distribution $(N=1000)$ of scattering radii $N\left(\mu_{r}=r_{\text {eff }} ; \sigma_{r}=0.15 r_{\text {eff }}\right)$ to eliminate ripples associated with Bessel function solutions to the Mie equations (Gardner and Sharp, 2010). The optimal $r_{\text {eff }}$ values are $\sim 9.3$ and $\sim 10.6 \mathrm{~mm}$ with corresponding specific surface areas $\sim 0.35$ and $\sim 0.31 \mathrm{~m}^{2} \mathrm{~kg}^{-1}$ for 20 and 21 July experimental values, respectively.

\subsection{Flux absorption coefficients}

Warren et al. (2006) developed a method to estimate $k_{\mathrm{abs}}$ for pure ice (i.e. $k_{\mathrm{abs}}^{\mathrm{ice}}$ ) from measurements of flux attenuation in snow in Antarctica. The method relies on three assumptions: (1) the value of $k_{\mathrm{abs}}^{\mathrm{ice}}$ at the reference wavelength $\left(\lambda_{0}=600 \mathrm{~nm}\right)$ is known accurately, (2) the value of $k_{\text {att }}$ at $\lambda_{0}$ is not affected by LAPs in the measured snow or ice, and (3) $\bar{\omega}(\lambda)$ varies so little as to be effectively independent of wavelength in the spectral range considered (here the nearUV and visible spectra). Warren et al. (2006) verified the validity of these assumptions for the spectral range of 350 $600 \mathrm{~nm}$ and obtained the following relation (Eq. 15 of that paper) between flux attenuation and flux absorption:

$\left[\frac{k_{\mathrm{att}}(\lambda)}{k_{\mathrm{att}}\left(\lambda_{0}\right)}\right]^{2} \approx\left[\frac{k_{\mathrm{abs}}(\lambda)}{k_{\mathrm{abs}}\left(\lambda_{0}\right)}\right]$.

Equation (14) assumes that $k_{\text {abs }}$ is not affected by LAPs at the reference wavelength $(600 \mathrm{~nm})$, but the relation can be used to estimate $k_{\text {abs }}$ at any other wavelength, including those where absorption is affected by LAPs. At those wavelengths, Eq. (14) will predict values for $k_{\mathrm{abs}}$ higher than $k_{\mathrm{abs}}^{\text {ice }}$ if LAPs are present in the measured snow or ice volume, due to the influence of LAPs on $k_{\text {att }}$.

The inferred $k_{\text {abs }}$ values can be related to a mass absorption cross section (MAC) (Doherty et al., 2010):

$k_{\mathrm{abs}}(\lambda)=k_{\mathrm{abs}}^{\mathrm{ice}}(\lambda)+\beta c \rho_{i}$,

where $\beta$ is the spectral MAC $\left(\mathrm{m}^{2} \mathrm{~kg}^{-1}\right)$ and $c$ is the mass mixing ratio of LAPs in the ice volume ( $\mathrm{g} \mathrm{LAPs}^{-1}$ ice). We exploit this to interpret differences between our theoretical and experimental values of $k_{\text {att }}$ on the basis of differences between $k_{\text {abs }}^{\text {ice }}$ (Warren et al., 2006) and the $k_{\text {abs }}$ values that we obtain for glacier ice from Eq. (14). To provide context, we use representative values of $\beta$ for black carbon $\beta_{\mathrm{BC}}$ and insoluble mineral dust (hereafter "dust") $\beta_{\text {dust }}$ to estimate corresponding equivalent mass mixing ratios $c_{\mathrm{eq}} \mathrm{BC}$ and $c_{\mathrm{eq}}$ dust (Di Mauro et al., 2017; Doherty et al., 2010). The "equivalent" mass mixing ratio is the mass mixing ratio of each LAP species required to explain the difference between $k_{\text {abs }}^{\text {ice }}$ and our inferred $k_{\mathrm{abs}}$ values at a reference wavelength, and it follows a similar approach to that used to infer LAP absorption in snowpack (Tuzet et al., 2019). For $\beta_{\mathrm{BC}}$, we use $6 \mathrm{~m}^{2} \mathrm{~g}^{-1}$ as a representative MAC at $550 \mathrm{~nm}$ and an absorption Ångström exponent range of $0.8-1.9$ to scale this value to $400 \mathrm{~nm}$ (Doherty et al., 2010). For $\beta_{\text {dust }}$, we use $0.013 \mathrm{~m}^{2} \mathrm{~g}^{-1}$ at $550 \mathrm{~nm}$ (Di Mauro et al., 2017) and an absorption Ångström exponent range of 2-3 (Doherty et al., 2010). We note that these descriptive estimates provide context for discussion; actual LAP species concentrations were not measured.

\subsection{Near-surface effects}

Equations (7) and (12) are applicable at distances far enough from the incident boundary (here the ice surface) that the ra- 
diation field is diffuse and $k_{\text {att }}$ is constant with depth. Near the ice surface the radiation field is converted via multiple scattering from direct to diffuse flux, and attenuation may be enhanced by direct reflection, enhanced scattering, and/or absorption by the granular near-surface ice microstructure or specular reflection at the ice surface, depending on its roughness (Dadic et al., 2013; Light et al., 2008; Mullen and Warren, 1988). To account for non-diffuse near-surface attenuation, we define a piecewise optical depth:

$\tau(\lambda)=\int_{0}^{z^{\prime}} k^{\prime}(\lambda) \mathrm{d} z+\int_{z^{\prime}}^{z} k_{\mathrm{att}}(\lambda) \mathrm{d} z$,

where $k^{\prime}$ is an effective attenuation coefficient for the nearsurface non-diffuse layer and $z^{\prime}$ is a depth chosen to partition this layer from the interior diffuse region. We estimate $k^{\prime}$ with a centred finite-difference form of Eq. (7):

$k^{\prime}(\lambda)=-\frac{1}{\Delta z^{\prime}} \ln \left[\frac{I_{z^{\prime}}(\lambda)}{I_{0}(\lambda)}\right]$.

Here, $\Delta z^{\prime}$ is $12 \mathrm{~cm}$ and $I_{z^{\prime}}$ is the $12 \mathrm{~cm}$ in-ice irradiance measured on 20 July. Accordingly, the asymptotic attenuation length (Eq. 9) is distinguished from an effective penetration depth $d_{\lambda}$ to include the effect of near-surface attenuation. The attenuation length is the depth at which $\tau=1$. Setting $\tau(\lambda)$ to 1 in Eq. (16) and solving for $z$ yields

$z=\frac{1-\Delta z^{\prime}\left[k^{\prime}(\lambda)-k_{\mathrm{att}}(\lambda)\right]}{k_{\mathrm{att}}(\lambda)}=d_{\lambda}$.

Equation (16) gives estimates of spectral transmittance that account for non-diffuse near-surface attenuation but relies on knowledge of $k^{\prime}$, which is sensitive to the spectral composition and directional distribution of $I_{0}$ and the structure and composition of the near-surface ice (Grenfell and Maykut, 1977; Light et al., 2008). To generalize the magnitude of near-surface attenuation, we calculate the fraction of downwelling spectral irradiance that transmits the nondiffuse layer weighted by the downwelling spectral irradiance:

$\chi_{0}=\int_{\lambda_{1}}^{\lambda_{2}} I_{0}(\lambda) \exp \left[-k_{\lambda}^{\prime} \Delta z^{\prime}\right] \mathrm{d} \lambda / \int_{\lambda_{1}}^{\lambda_{2}} I_{0}(\lambda) \mathrm{d} \lambda$.

The $\chi_{0}$ parameter is analogous to the $i_{0}$ parameter introduced by Grenfell and Maykut (1977) to partition the fraction of solar irradiance absorbed in the upper $10 \mathrm{~cm}$ of sea ice, which they termed the "surface scattering layer" (SSL), and the ice interior, in which radiation is exponentially absorbed at a constant rate:

$i_{0}=\int_{\lambda_{1}}^{\lambda_{2}}\left[1-\alpha_{\lambda}\right] I_{0}(\lambda) \exp \left[-k_{\lambda}^{\prime} \Delta z^{\prime}\right] \mathrm{d} \lambda / \int_{\lambda_{1}}^{\lambda_{2}}\left[1-\alpha_{\lambda}\right] I_{0}(\lambda) \mathrm{d} \lambda$.
The $i_{0}$ parameter has been widely adopted in energy balance models of glaciers and sea ice to compute subsurface flux divergence (heating rates) when radiation penetration is considered important (Bintanja and Van Den Broeke, 1995; Hoffman et al., 2014; Holland et al., 2012). For example, the sea ice component of the Community Earth System Model (CESM) uses $i_{0}=70 \%$ for the visible $(200-700 \mathrm{~nm})$ and $i_{0}=0 \%$ for the infrared $(700-5000 \mathrm{~nm})$ (Briegleb and Light, 2007). The important distinction is that $i_{0}$ partitions the absorbed flux whereas $\chi_{0}$ partitions the downward flux (Brandt and Warren, 1993). For both $\chi_{0}$ and $i_{0}$, we set $\Delta z^{\prime}$ to $10 \mathrm{~cm}$ for consistency with prior work (Grenfell and Maykut, 1977; Light et al., 2008; Maykut and Untersteiner, 1971).

\subsection{Monte Carlo simulations of detector interference}

We developed a Monte Carlo radiative transfer model to estimate the effect of detector interference on measured irradiances and fitted $k_{\text {att }}$ values, following methods developed to simulate light propagation in biological tissue, ocean waters, and sea ice (Leathers et al., 2004; Light et al., 2003; Wang et al., 1995). Photon scattering is specified by a HenyeyGreenstein scattering phase function with single-scattering properties $Q_{\text {ext }}(\lambda), g(\lambda)$, and $\bar{\omega}(\lambda)$ inferred from our optical measurements (Sect. 2.5). A complete technical description is given in the Supplement, where model accuracy is verified by comparison with benchmark solutions to the radiative transfer equation (van de Hulst, 1980).

In the Monte Carlo simulations, photons are launched from an irradiance sensor on a detector rod with dimensions identical to those reported in this study. In the ideal (baseline) simulation, photons originate from an isotropic point source and propagate through ice until they transmit the surface or are terminated by absorption. Detector interference is investigated by repeating the Monte Carlo simulations with an ideal cosine source function describing the angular response to radiance of the RCR and with a non-ideal (empirical) angular response function (Fig. 2), with and without scattering and absorption interference by the PVC detector rod. The detector rod albedo $\bar{\omega}_{\text {rod }} \approx 0.4$ is calculated from the absorption spectra of polyvinyl chloride (Zhang et al., 2020); scattering by the rod is assumed isotropic. The Monte Carlo model is integrated over 10000 interactions at nine wavelengths in $50 \mathrm{~nm}$ increments from 350 to $750 \mathrm{~nm}$, allowing us to fit the wavelength dependence of the estimated systematic uncertainty in simulated $k_{\text {att }}$ values.

\subsection{Uncertainty propagation}

Unless stated otherwise, all statistical uncertainties reported in this paper are standard errors that correspond to $68 \%$ confidence intervals around the mean (Taylor and Kuyatt, 1994). For an individual measurement with standard deviation $s_{i}$ and sample size $N \geq 30$, the standard error is $s_{i} / \sqrt{N}$. For 

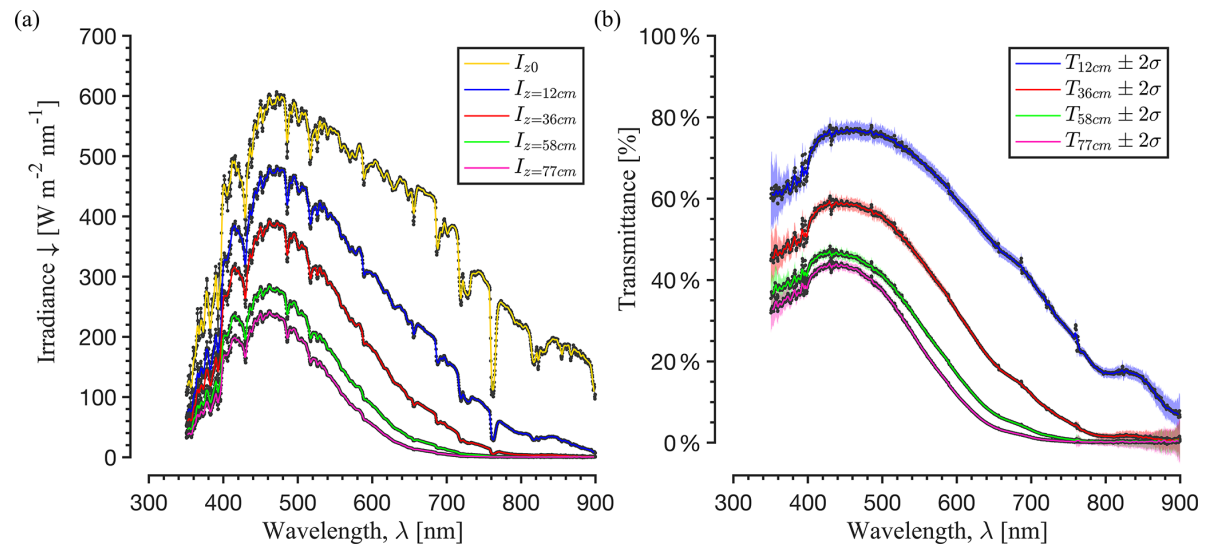

Figure 4. (a) Field spectra of surface downwelling $(z=z 0)$ and in-ice irradiance at four depths below the ice surface collected on $20 \mathrm{July} 2018$ (Layer A) between 13:45 and 14:35 local time in the western Greenland ablation zone $\left(67.15^{\circ} \mathrm{N}, 50.02^{\circ} \mathrm{W}\right)$. Raw data were recorded at a $1 \mathrm{~Hz}$ frequency for $30 \mathrm{~s}$, yielding 30 irradiance profiles at each depth. Shown here are $30 \mathrm{~s}$ averages at a $\sim 0.35 \mathrm{~nm}$ spectral resolution for each depth (black dots) and $1 \mathrm{~nm}$ interpolated values smoothed with a $3 \mathrm{~nm}$ centred moving mean filter for clarity (continuous lines). (b) Transmittance at each depth, with $30 \mathrm{~s}$ averages (black dots), $1 \mathrm{~nm}$ interpolated values (continuous lines), and shaded bounds ( $\pm 2 \sigma)$ representing propagated measurement uncertainty deduced from the standard deviations of the $1 \mathrm{~Hz}$ raw data $(N=30$ for each value). Results for the $21 \mathrm{July} 2018$ (Layer B) experiment (not shown) are qualitatively similar.

$N<30$, standard errors are scaled by a critical $t$ value drawn from Student's $t$ distribution. Standard errors for combined quantities are propagated in quadrature and hereafter referred to as combined uncertainty. The combined uncertainty for spectral irradiance $I(\lambda)$ is

$\sigma_{\mathrm{I}}=\sqrt{\left(\sigma_{\mathrm{I}}^{*}\right)^{2}+\left(\sigma_{\mathrm{D}}\right)^{2}}$,

where $\sigma_{\mathrm{I}}^{*}$ is the standard deviation of the high-frequency irradiance spectra before dark-noise correction and $\sigma_{\mathrm{D}}$ is the standard deviation of the high-frequency dark-noise spectra. An analogous procedure is used to estimate the combined uncertainty for calibrated irradiance. The combined uncertainty for spectral transmittance $T(\lambda)$ is

$\sigma_{T}=T \sqrt{\left(\frac{\sigma_{I_{z}}^{\mathrm{cal}}}{I_{z}^{\mathrm{cal}}}\right)^{2}+\left(\frac{\sigma_{I_{0}}}{I_{0}}\right)^{2}}$,

where $\sigma_{I_{z}}^{\text {cal }}$ and $\sigma_{I_{0}}$ are the combined uncertainties for calibrated in-ice irradiance and dark-noise-corrected surface downwelling irradiance, respectively. The combined uncertainty for optical depth $\tau_{\lambda}$ is

$\sigma_{\tau}=\frac{\sigma_{T}}{T}$,

and the combined uncertainty for $k_{\text {att }}$ is

$\sigma_{k}=\sqrt{\left(\sigma_{\Delta \tau}\right)^{2}+\left(\sigma_{\Delta z}\right)^{2}}$.

Equation (24) gives a first-order description of $\sigma_{k}$ due to statistical propagation of measurement uncertainties, neglecting higher-order interaction terms. A description of the statistical uncertainty in fitted $k_{\text {att }}(\lambda)$ values is given by the MLE of the regression slope of Eq. 8, which can be expressed in terms of an error model as

$\hat{\tau}_{z}(\lambda)=\tau_{0}(\lambda)+k_{\text {att }}(\lambda)\left(\Delta \hat{z}+\varepsilon_{\Delta z}\right)+\varepsilon_{\Delta \tau}$,

where $\hat{\tau}$ and $\Delta \hat{z}$ are the true but unobserved (due to measurement error) optical depth and ice thickness and $\varepsilon_{\Delta z} \sim$ $N\left(0, \sigma_{\Delta z}^{2}\right)$ and $\varepsilon_{\Delta \tau} \sim N\left(0, \sigma_{\Delta \tau}^{2}\right)$ are normally distributed error terms. Unlike ordinary least squares, MLE gives an unbiased estimate of the slope and standard error of a linear functional relationship between two variables measured with error (York et al., 2004). The method has been used in similar studies to infer optical coefficients (Zieger et al., 2011). The MLE standard errors for $k_{\text {att }}(\lambda)$ are adjusted for $N-2$ degrees of freedom with a two-sided $t$ statistic (Cantrell, 2008) and combined in quadrature with systematic uncertainty estimated from Monte Carlo simulation to estimate total combined uncertainty for reported $k_{\text {att }}(\lambda)$ values.

\section{Results}

\subsection{Spectral transmittance}

Four in-ice irradiance spectra were collected at 12, 36, 58, and $77 \mathrm{~cm}$ depth below the ice surface on 20 July (hereafter referred to as Layer A) (Fig. 4a) and at 53, 67, 82, and $124 \mathrm{~cm}$ on 21 July (hereafter referred to as Layer B). At all depths, spectral transmittance $T$ is maximal at $430 \mathrm{~nm}$ and maintains relatively stable and high values at wavelengths up to $\sim 500 \mathrm{~nm}$ in the visible, beyond which $T$ decreases into the red end of the visible spectrum following the well-known exponential increase in ice absorptivity (Fig. 4c). Maximum 

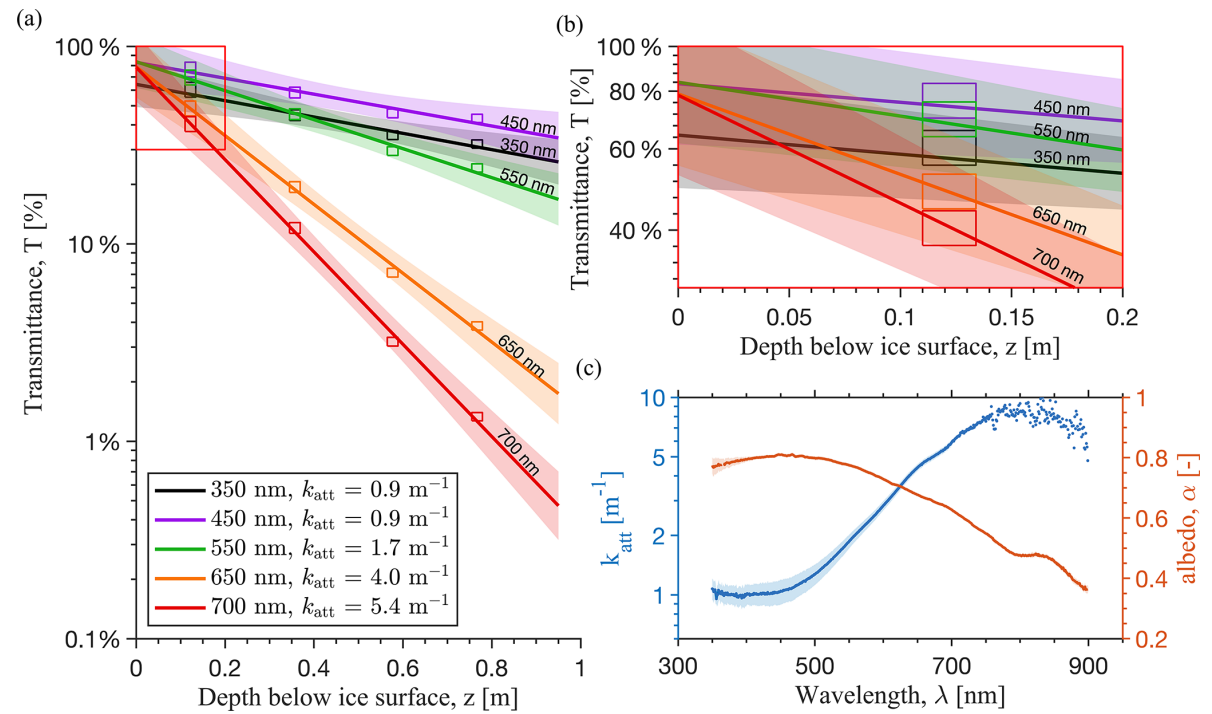

Figure 5. (a) Sample linear regressions between measured transmittance (indicated by rectangles with width and height proportional to measurement uncertainty in both variables) and depth in the range of 12-77 cm (Layer A) at five representative wavelengths spanning the measured spectral range. The slope of each line is the attenuation coefficient $k_{\text {att }}$. Shaded bounds are $\pm 95 \%$ confidence intervals from a two-sided $t$ distribution. (b) Red box inset in (a) shows the $y$-axis intercept of each regression is less than $100 \%$, indicating the magnitude of deviation from Bouguer's law near the surface. (c) Spectral $k_{\text {att }}$ (blue dots with shaded uncertainty; left axis) and spectral albedo (red dots with shaded uncertainty; right axis). Beyond $\sim 700 \mathrm{~nm}$, in-ice transmitted irradiance is too low to reliably estimate $k_{\text {att }}$ (see Figs. $4 \mathrm{a}$ and $2 \mathrm{c}$ ), as indicated by the increased scatter in $k_{\text {att }}$ values.

$T$ values vary from $78 \%$ at $12 \mathrm{~cm}$ to $45 \%$ at $77 \mathrm{~cm}$. For wavelengths $>500 \mathrm{~nm}, T$ rapidly decreases both with wavelength and with depth; beyond $\sim 800 \mathrm{~nm}$ nearly all incident light is attenuated within $36 \mathrm{~cm}$ of the ice surface, although substantial attenuation is apparent in the $12-36 \mathrm{~cm}$ depth region (Fig. 4b). The standard deviation of the $1 \mathrm{~Hz}$ raw data is $<1 \mathrm{~W} \mathrm{~m}^{-2} \mathrm{~nm}^{-1}$ at all wavelengths, consistent with field observations of thick cloud cover and diffuse light conditions described in Sect. 2.2. Instrumental noise and highfrequency measurement variations propagate as $\pm 1.6 \%$ uncertainty on $T$ for wavelengths between $400-600 \mathrm{~nm}, \pm 1 \%-$ $8 \%$ for wavelengths between $350-400 \mathrm{~nm}$, where instrumental noise is higher, and $\pm 1 \%-12 \%$ uncertainty for wavelengths between $600-750 \mathrm{~nm}$, where noise is higher and light levels are low.

\subsection{Experimental flux attenuation coefficients and albedo}

Fitted $k_{\text {att }}$ values for Layer A range from $0.98 \pm 0.17$ to $7.86 \pm 0.43 \mathrm{~m}^{-1}$ for wavelengths between $350-750 \mathrm{~nm}$ (Fig. 5a), with uncertainty bounds that represent combined statistical and systematic uncertainty (see Sect. 4 for a discussion of systematic error). These values correspond to attenuation lengths of $1.02 \pm 0.18$ to $0.13 \pm 0.007 \mathrm{~m}$, respectively. Layer B $k_{\text {att }}$ values are $\sim 12 \%$ lower than Layer A values at $350-500 \mathrm{~nm}$ and within $1 \%$ at $650 \mathrm{~nm}$ (see inset Fig. 6). For Layer A, the minimum in $k_{\text {att }}$ is at $390 \mathrm{~nm}$, blueshifted relative to the maximum in $T$ at $430 \mathrm{~nm}$. For Layer B, the minimum is at $397 \mathrm{~nm}$. The coefficient of determination $\left(r^{2}\right)$ ranged from $0.96-1.0(p<0.01)$, with a median value of 0.98 , suggesting the data are described appropriately by the Bouguer-law exponential decay model up to $\sim 700 \mathrm{~nm}$, beyond which measured values of in-ice irradiance at 58 and $77 \mathrm{~cm}$ depth were too low to reliably fit $k_{\text {att }}$ values (see Figs. $4 \mathrm{~b}$ and $5 \mathrm{c}$ ). For Layer B values, low light levels prevented fits beyond $\sim 650 \mathrm{~nm}$.

Albedo spectra correspond closely to patterns in transmittance and attenuation (Fig. 5c). The near-UV and blue wavelengths that efficiently transmit ice mostly re-emerge as reflected light, owing to the extremely low values of ice absorptivity in the wavelength range $350-500 \mathrm{~nm}$ where albedo is maximum (Gardner and Sharp, 2010; He and Flanner, 2020; Warren et al., 2006). The maximum measured albedo value is $0.81 \pm 0.004$ at $452 \mathrm{~nm}$, further red-shifted from the minimum in $k_{\text {att }}$ and the maximum in $T$. All three quantities have low variability near the minimum; albedo is 0.79 at $390 \mathrm{~nm}$. The broadband albedo $\alpha$ (Eq. 11) for the $350-900 \mathrm{~nm}$ wavelength range is $0.70 \pm 0.006$, which is high but not atypical for melting white ice under overcast skies (Bøggild et al., 2010).

\subsection{Theoretical flux attenuation coefficients}

Asymptotic $k_{\text {att }}$ values predicted by two-stream theory for optically clean bubbly ice are nearly 1 order of magnitude lower than field estimates for wavelengths $<500 \mathrm{~nm}$, where very small concentrations of LAPs in the measured ice vol- 


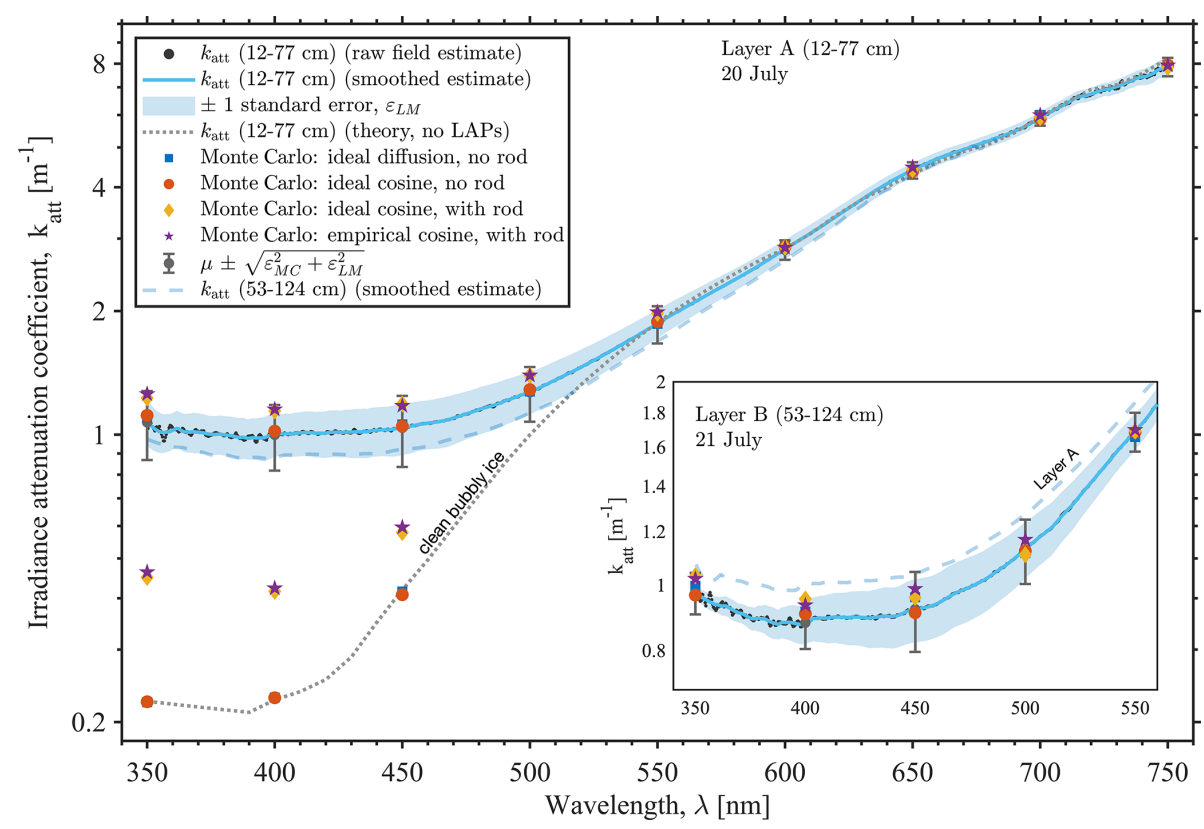

Figure 6. Visible and near-UV irradiance attenuation coefficient $k_{\text {att }}$ spectra from measurements of light transmission in bare glacier ice collected on 20 July 2018 at 12-77 cm depth below the ice sheet surface. Field estimates are compared with asymptotic two-stream theory for optically clean bubbly ice (continuous dotted line) and with values at nine wavelengths from four simulations with a three-dimensional Monte Carlo radiative transfer model (solid symbols). Monte Carlo values for clean bubbly ice are shown for 350 , 400 , and $450 \mathrm{~nm}$ to demonstrate detector interference at these wavelengths; values at wavelengths $>550 \mathrm{~nm}$ converge with field spectra and are omitted for clarity. Two measures of uncertainty are shown: (1) statistical linear model uncertainty $\varepsilon_{\mathrm{LM}}$ (shaded uncertainty bounds; \pm 1 standard error in the linear regression) and (2) $\varepsilon_{\mathrm{LM}}$ combined with systematic uncertainty $\varepsilon_{\mathrm{MC}}$ due to detector interference estimated with Monte Carlo simulation (error bars; $\mu \pm \varepsilon$ ). The same comparison for the 21 July experiment (inset; Layer B) suggests detector interference is within statistical uncertainty at wavelengths $>400 \mathrm{~nm}$.

ume dominate absorption (compare dotted grey line to solid blue line, Fig. 6) (Warren et al., 2006). In contrast, field estimates and two-stream theory converge at wavelengths $>540 \mathrm{~nm}$ where absorption is dominated by grain-size effects (He et al., 2017; Libois et al., 2013). The magnitude of inferred absorption enhancement in the visible due to LAPs (the quantity $\beta c \rho_{i}$ in Eq. 15 ) varies from $0.009-0.015 \mathrm{~m}^{-1}$ at $350-530 \mathrm{~nm}$. The equivalent black carbon concentration $c_{\text {eq }} \mathrm{BC}$ inferred at $400 \mathrm{~nm}$ is $1-2 \mathrm{ng} \mathrm{g}^{-1}$ for both Layer A and Layer $\mathrm{B}$, where the range covers uncertainty in both the absorption spectra and the absorption Ångström exponent (Doherty et al., 2010). The equivalent mineral dust concentration $c_{\text {eq }}$ dust is $\sim 344-620 \mathrm{ng} \mathrm{g}^{-1}$ for Layer A and 303$545 \mathrm{ng} \mathrm{g}^{-1}$ for Layer B. Monte Carlo simulations without detector interference replicate both asymptotic theory for clean bubbly ice (i.e. when forced with $k_{\text {abs }}^{\text {ice }}$ ) and field estimates when forced with $k_{\text {abs }}$ values inferred from our optical measurements (solid blue squares, Fig. 6). Monte Carlo simulations of detector interference are discussed further in Sect. 4 .

\subsection{Near-surface attenuation and effective penetration depth}

Near the ice surface irradiance is not attenuated exponentially and Bouguer's law does not hold, as indicated by the $y$ intercepts of the straight lines in Fig. $5 \mathrm{~b}$ at values $<100 \%$. Effective $k^{\prime}$ values (Eq. 17) for the quasi-granular 0-12 cm layer are $\sim 1.5$ times higher than $k_{\text {att }}$ values for interior bubbly ice at $12-77 \mathrm{~cm}$ depth for wavelengths $>570 \mathrm{~nm}$ and are up to 4 times higher between $400-570 \mathrm{~nm}$ (Fig. 7). Owing to higher near-surface attenuation, transmitted irradiance $I_{z}$ is overestimated by $10 \%-60 \%$ if Bouguer's law is applied to the incident downwelling irradiance $I_{0}$ using asymptotic $k_{\text {att }}$ values, with median overestimation of $23 \%$ (Fig. 8a). In contrast, the piecewise optical depth (Eq. 16) predicts $I_{z}$ to within $12 \%$ of measured values for all wavelengths between $350-700 \mathrm{~nm}$ with a median error of $3 \%$. Integrated over these wavelengths, $\chi_{0}$ is 0.68 and $i_{0}$ is 0.66 , suggesting $66 \%$ of the total incoming irradiance within this spectral region is absorbed at depths below $10 \mathrm{~cm}$. If $k_{\text {att }}$ is used rather than $k^{\prime}$ to calculate $\chi_{0}$ and $i_{0}$, the respective values are 0.81 and 0.79 .

Stated in terms of penetration depth, $d_{\text {eff }}$ varies from 12 $84 \mathrm{~cm}$ between $350-700 \mathrm{~nm}$. These values are $13 \%-44 \%$ 


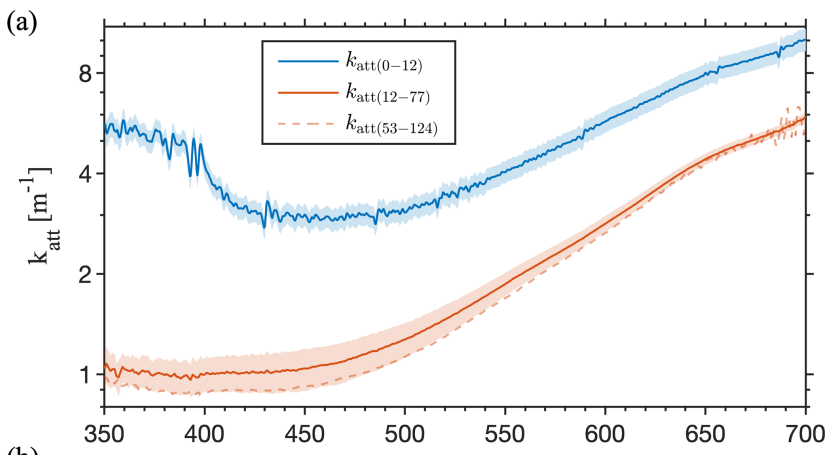

(b)

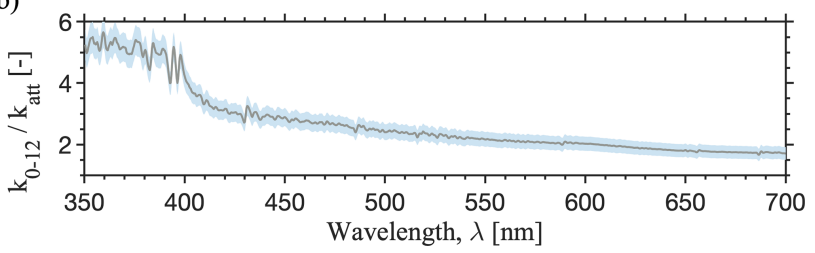

Figure 7. (a) Effective attenuation coefficient $k^{\prime}$ for the near-surface $0-12 \mathrm{~cm}$ region compared to $k_{\text {att }}$ values estimated for the interior 12-77 cm (Layer A) and 53-124 cm (Layer B) depth regions. (b) Effective $k^{\prime}$ values are $\sim 1.6$ times larger than Layer $\mathrm{A}$ values at wavelengths beyond about $600 \mathrm{~nm}$ but are $\sim 2-4$ times larger between $400-600 \mathrm{~nm}$. The spectral dependence suggests a higher influence of absorptive impurities on attenuation enhancement near the ice surface than in the ice interior. The shaded bounds on $k^{\prime}$ represent propagated $\pm 1.2 \mathrm{~cm}$ vertical measurement uncertainty.

lower than attenuation lengths $l_{\text {att }}$ inferred from empirical asymptotic $k_{\text {att }}$ values. Specifically at $532 \mathrm{~nm}, d_{\text {eff }}$ is $52 \mathrm{~cm}$, or $10 \mathrm{~cm}$ lower than the $62 \mathrm{~cm}$ empirical $l_{\text {att }}$ value and $14 \mathrm{~cm}$ lower than the $66 \mathrm{~cm}$ theoretical $l_{\text {att }}$ value for optically pure bubbly ice. These results point to the potential for reduced optical penetration due to enhanced scattering and absorption on or near the ice surface, as well as within the ice volume where small LAP concentrations reduce optical backscattering due to enhanced absorption.

For smooth ice surfaces, attenuation may be enhanced by refraction at the ice-air interface (Mullen and Warren, 1988). If present, a refractive boundary would enhance near-surface attenuation via external specular reflection, and possibly via enhanced near-surface absorption of the internally reflected downward flux. Following Briegleb and Light (2007; Eq. 2024), we calculate the external diffuse specular reflectivity for a flat ice surface to be 0.063 , meaning specular reflection could enhance attenuation by up to $6.3 \%$. This value is smaller than the $18 \%-44 \%$ near-surface attenuation implied by the $y$ intercepts in Fig. 5b, suggesting specular reflection alone cannot explain the discrepancy. Instead, we suggest that enhanced scattering by the granular near-surface ice microstructure, together with absorptive impurities, enhance near-surface light attenuation at our field site, consistent with observations of the granular and porous surface layer on sea ice (Grenfell and Maykut, 1977; Light et al., 2008).
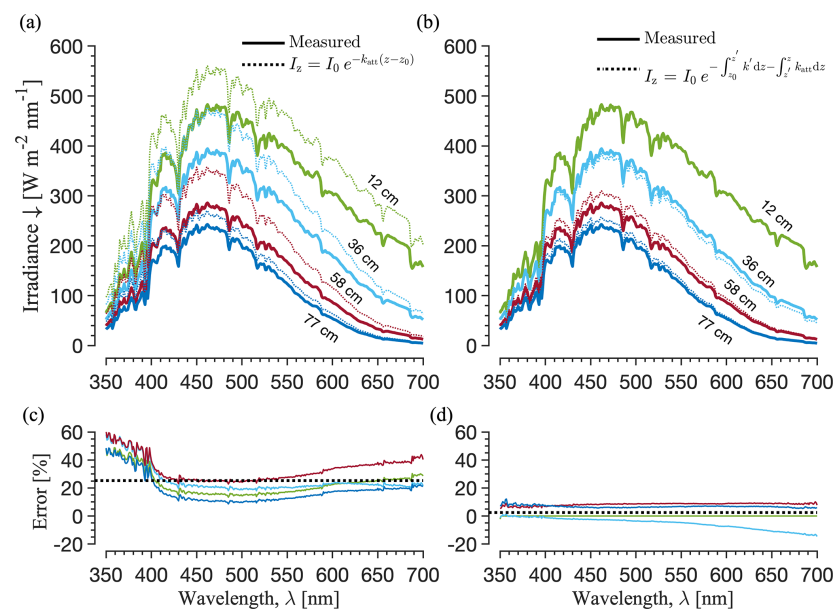

Figure 8. Measured in-ice irradiance compared with (a) Bouguer's law (Eq. 7) with no modification and (b) the piecewise Bouguer's law (Eq. 16). The error structure (c, d) provides insight into the near-surface attenuation processes: relative errors $(\%)$ are positive (model underpredicts attenuation) at all wavelengths but are highest in the near-UV, lowest in the blue, and increase monotonically into the red end of the visible spectrum. (d) Errors are small and generally decrease monotonically with increasing wavelength. Taken together, near-surface attenuation enhancement is $\sim 10 \%-60 \%$.

\section{Uncertainty analysis}

The effect of random and systematic uncertainties on our optical measurements and fitted $k_{\text {att }}$ values is evaluated with Monte Carlo simulation and statistical analysis. We considered systematic uncertainties in detector positions, spectrometer sensitivity to dark current, the non-ideal angular response of the irradiance sensor, and attenuation interference by the PVC detector rod.

The detector positions are known to within $0.9 \pm 0.4 \mathrm{~cm}$ from independent measurements of the vertical ice thickness $\Delta h$. The in situ ice density $\rho$ varied from $801-888 \mathrm{~kg} \mathrm{~m}^{-3}$ between $4-124 \mathrm{~cm}$ where irradiances were measured. The variation in $\rho$ was examined by repeating the analysis with $\Delta z$ values computed with a single depth-weighted average $\rho$ applied to each $\Delta h$ value and with $\rho$ values estimated for each $\Delta h$ value from linear and cubic interpolation of the vertical density profile. The maximum $\Delta z$ difference was $0.9 \mathrm{~cm}$. The $k_{\text {att }}$ values differed by $<1 \%$, and $r^{2}$ values were nearly identical. We use the depth-weighted average $\rho$ values to calculate $\Delta z$, which is 835 and $855 \mathrm{~kg} \mathrm{~m}^{-3}$ for the measurements collected on 20 and 21 July, respectively.

Detector position uncertainty was further assessed by fitting $k_{\text {att }}$ values with an ensemble of $10000 \Delta z$ values perturbed with random errors drawn from a normal distribution $N(\mu=0.9 \mathrm{~cm} ; \sigma=0.4 \mathrm{~cm})$. At all wavelengths, the chance of obtaining a fitted $k_{\text {att }}$ value $>2 \%$ from the mean value was $<5 \%$. We take $2 \%$ as a conservative estimate of systematic uncertainty due to ice thickness measurement bias. 


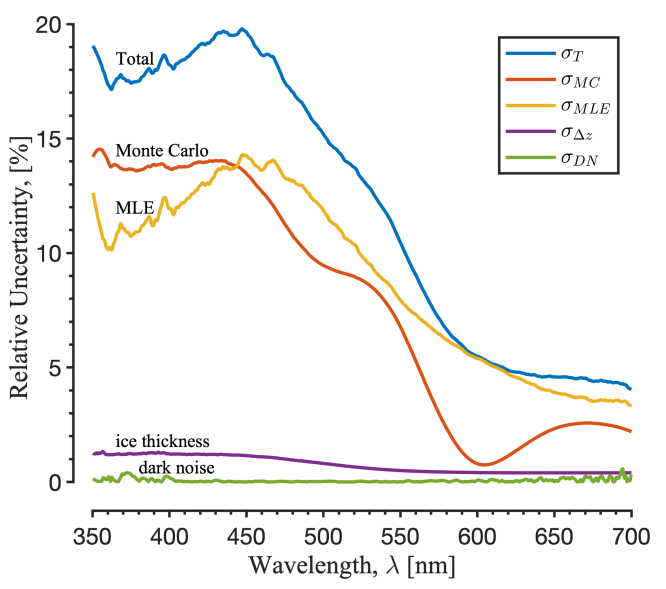

Figure 9. Uncertainty budget for reported asymptotic attenuation coefficient $k_{\text {att }}$ values for the $12-77 \mathrm{~cm}$ depth region (Layer A). Systematic uncertainties examined include spectrometer sensitivity to dark noise, ice thickness (detector position) measurement uncertainty, the non-ideal angular response of the irradiance sensor, and scattering and absorption interference by the polyvinyl chloride detector rod (estimated with Monte Carlo simulation). These systematics are combined with statistical uncertainty represented by 1 standard error in the maximum likelihood estimation (MLE) linear regression fits. Values for Layer B (53-124 cm) (not shown) are qualitatively similar but lower, with total uncertainty $<14 \%$ in the region of maximum uncertainty.

As described in Sect. 3, all irradiance spectra are corrected for residual dark noise. The noise may have varied during the experiment, and dark-noise measurements with the in-ice spectrometer were made on the surface, rather than within the ice. To assess possible bias, we fit $k_{\text {att }}$ values with and without residual dark-noise correction. The mean difference was $-0.01 \pm 0.13 \%$ averaged over the $350-700 \mathrm{~nm}$ wavelength range. For a few discrete wavelengths between $350-400 \mathrm{~nm}$ and $700-750 \mathrm{~nm}$, differences approached $2 \%$. These wavelengths are those with the highest dark noise in the reference spectrometer (Fig. 2). At wavelengths between $400-700 \mathrm{~nm}$, differences were $<0.5 \%$.

Monte Carlo simulations indicate a possible $+1 \%-14 \%$ systematic bias due to detector interference for Layer A values, and $+2 \%-8 \%$ for Layer B values (Fig. 9; also see purple stars minus solid squares, Fig. 6). The high end of this range applies to the wavelength region of minimum absorption of $\sim 350-450 \mathrm{~nm}$. The simulated bias is within statistical uncertainty at wavelengths $>450 \mathrm{~nm}$ for Layer A and at wavelengths $>400 \mathrm{~nm}$ for Layer B (Fig. 9). The nonideal cosine response of the RCR and the presence of the detector rod both tend to increase $k_{\text {att }}$ values relative to the ideal case, as expected given the low albedo of the detector rod. However, detector interference is masked somewhat by the presence of LAPs, as indicated by the larger simulated interference for bubbly ice without LAPs (see dotted grey line and associated Monte Carlo values, Fig. 6). Over- all, the combined statistical and systematic uncertainty for the $350-450 \mathrm{~nm}$ region is $<20 \%$ for Layer A values and $<14 \%$ for Layer B values and as low as $\sim 5 \%$ for wavelengths $>450 \mathrm{~nm}$ (Fig. 9).

\section{Discussion}

\subsection{Comparison with attenuation spectra for sea ice, snowpack, and deep glacial ice}

We report spectral measurements of near-UV and visible light transmission in bare ablating glacier ice. These measurements are used to estimate irradiance attenuation coefficients $k_{\text {att }}$ for the spectral range $350-750 \mathrm{~nm}$. Prior studies quantified $k_{\text {att }}$ for sea ice and snowpack (e.g. Fisher et al., 2005; Frey et al., 2011; Gerland et al., 2000; Grenfell and Maykut, 1977; Järvinen and Leppäranta, 2013; King and Simpson, 2001; Light et al., 2008; Meirold-Mautner and Lehning, 2004; Pegau and Zaneveld, 2000; Picard et al., 2016; Tuzet et al., 2019; Warren et al., 2006). Scattering and absorption coefficients were quantified for compressed South Pole glacial ice at $800-2350 \mathrm{~m}$ depth by the AMANDA (Antarctic Muon and Neutrino Detector Array) experiment (Ackermann et al., 2006; Askebjer et al., 1995, 1997). For South Pole ice at $800-1000 \mathrm{~m}$ depth, visible and near-UV light scatters on air bubbles, below which bubbles transition under pressure to non-scattering clathrates and light scatters on dust grains (Price and Bergström, 1997b). In the bubblyice regime studied by AMANDA, $k_{\mathrm{sca}}$ values at $532 \mathrm{~nm}$ are $\sim 1-3 \mathrm{~m}^{-1}$, comparable to the $1.6 \mathrm{~m}^{-1}$ value quantified in this study. Light scattering in the dusty-ice regime $(>1000 \mathrm{~m}$ depth) is not comparable to this study; absorption by dust is discussed below.

Figure 10 compares our $k_{\text {att }}$ spectra for glacier ice to seven previously published spectra for snowpack and sea ice. In general, glacier ice is the most transparent structure examined with the exception of multi-year and first-year interior sea ice at wavelengths $>540 \mathrm{~nm}$ (Grenfell et al., 2006). Light attenuation in sea ice is controlled by its unique vertical composition including brine inclusions, air pockets, solid salts, sea ice algae, dissolved organic matter, water saturation, and radiative interactions between the ice and underlying ocean (Perovich, 1996). The latter factor, together with differences in optically equivalent grain size, may explain the low attenuation at longer wavelengths for sea ice shown here. Relative to snowpack in Greenland and Antarctica (Järvinen and Leppäranta, 2013; Meirold-Mautner and Lehning, 2004; Warren et al., 2006), attenuation by glacial ice has similar spectral structure but is lower at all wavelengths, reflecting the higher specific surface area of fine-grained polar snow. Attenuation within the surface scattering layer (SSL) of sea ice is intermediate, with spectral structure similar to snowpack and glacial ice. Attenuation at $5 \mathrm{~cm}$ depth in snow near Summit, Greenland, is the highest of all, possibly due to direct light scat- 


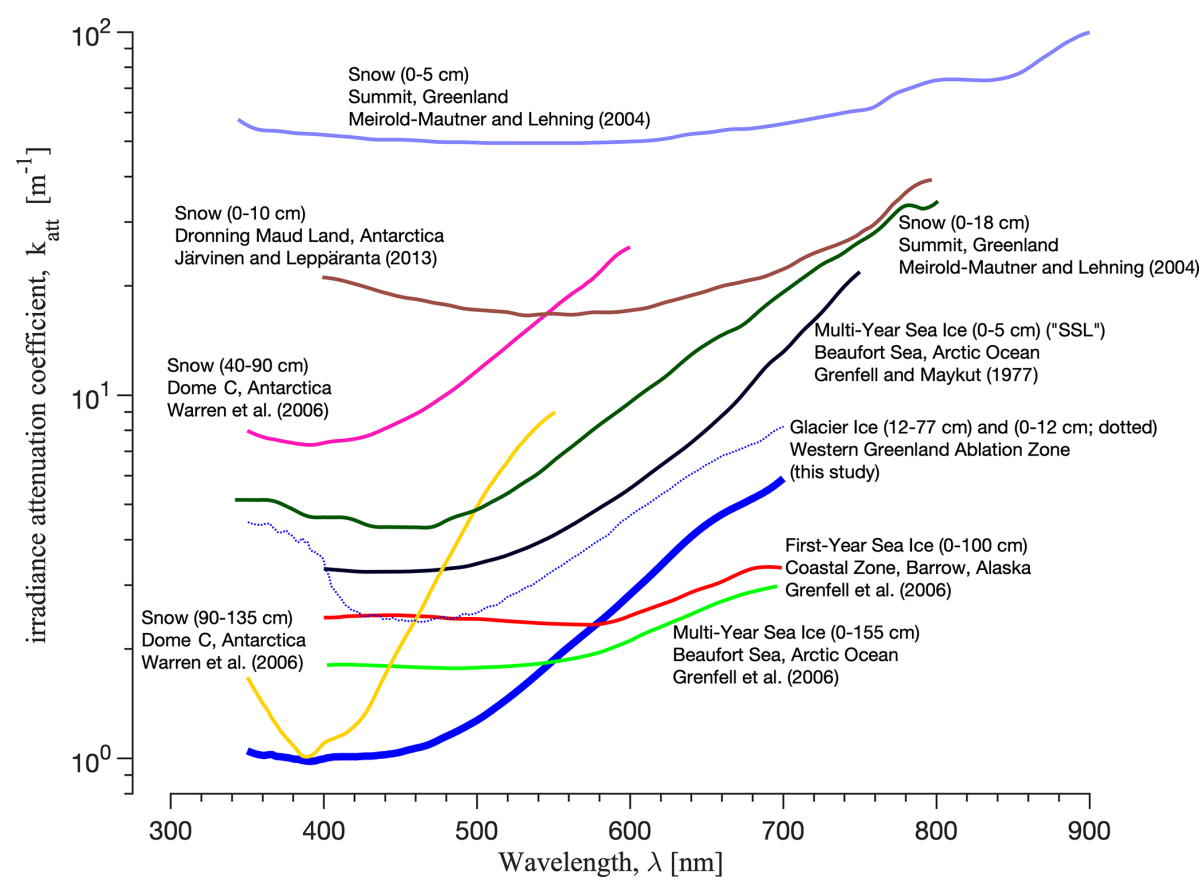

Figure 10. Attenuation coefficient spectra for seven distinct ice structures (from lower left clockwise): interior of clean, dry snowpack $\left(r_{\text {eff }} \approx 10^{-5} \mathrm{~m}\right)$ near Dome $C$ in Antarctica for two depth regions $(90-135 \mathrm{~cm}$ and $40-90 \mathrm{~cm})$ (Warren et al., 2006); near-surface $(0-10 \mathrm{~cm})$ dry snowpack $\left(r_{\text {eff }} \approx 10^{-3} \mathrm{~m}\right)$ in Dronning Maud Land, Antarctica (Järvinen and Leppäranta, 2013); near-surface $(0-5 \mathrm{~cm})$ and interior $(0-$ $18 \mathrm{~cm})$ dry snowpack $\left(r_{\mathrm{eff}} \approx 10^{-4} \mathrm{~m}\right)$ near Summit, Greenland (Meirold-Mautner and Lehning, 2004); surface scattering layer (SSL; 0-5 cm) of multi-year sea ice in the Arctic Ocean (Grenfell and Maykut, 1977); interior of ablating glacier ice in Greenland (this study) (12-77 cm in solid line; 0-12 cm in dotted line); interior of first-year sea ice in the coastal zone near Barrow, Alaska (Grenfell et al., 2006); and interior of multi-year sea ice in the Arctic Ocean (Grenfell et al., 2006). Differences in attenuation magnitude at each wavelength are mostly controlled by structural differences that control scattering, whereas spectral differences are mostly controlled by differences in type and concentration of absorbing impurities.

tering in the near-surface optical boundary layer. The comparison demonstrates that $k_{\text {att }}$ values vary by nearly 2 orders of magnitude at visible wavelengths due to differences in ice structure and composition.

At visible wavelengths between $350-530 \mathrm{~nm}$ our field estimates of $k_{\text {att }}$ are up to 1 order of magnitude larger than those obtained from two-stream theory for optically pure bubbly ice, consistent with selective absorption by mineral dust, black carbon, and microorganisms found on glaciers and ice sheet surfaces (Bøggild et al., 2010; Ryan et al., 2018; Stibal et al., 2017; Takeuchi, 2002; Yallop et al., 2012). For context, the absorptivity we document at $400 \mathrm{~nm}$ for Layer B can be explained by $1.2-1.8 \mathrm{ng} \mathrm{g}^{-1}$ (parts per billion, ppb) equivalent black carbon concentration. Values for Layer A are 1.4-2.0 ppb. Both estimates are relative to pure-ice absorptivity values reported by Warren et al. (2006). These values are within the range of $2 \pm 2 \mathrm{ppb}$ reported for clean snow near DYE-2 on the interior Greenland Ice Sheet considered representative of pre-industrial fallout rates (Doherty et al., 2010). The equivalent mineral dust concentration is $\sim 344$ 620 ppb for Layer A and 303-545 ppb for Layer B.

Relative to South Pole ice, our absorptivity values broadly agree with AMANDA values within two depth regions cor- responding to peaks in atmospheric-dust concentration during the Last Glacial Maximum (LGM) and Marine Isotope Stage 4 (MIS-4) glacial periods $\sim 23000$ and $\sim 66000$ years before present (Fig. 11). For these periods in Earth's history, Southern Hemisphere dust concentrations inferred from the Vostok and Dome C ice cores are 300-1500 ppb (Muhs, 2013; Petit et al., 1999). Hemispherical dust fluxes are generally synchronous at these timescales; similar peaks at the LGM and MIS-4 are observed in Greenland ice cores (Ruth et al., 2003). However, Northern Hemisphere dust concentrations are several times higher (Muhs, 2013; Ruth et al., 2003), meaning correlation with South Pole absorptivity does not map age at our site. Rather, our optical measurements are consistent with the relatively low dust concentrations during Northern Hemisphere warm periods. For the western Greenland ablation zone, alternating bands of visibly dark and bright outcropping ice are associated with periods of higher and lower aeolian activity during both the Early Holocene (post-LGM) and Late Pleistocene, with a characteristic band of older brighter interglacial ice $\sim 0.7-1 \mathrm{~km}$ from the margin where our field site is located (Bøggild et al., 2010; Petrenko et al., 2006; Reeh et al., 2002; Wientjes et al., 2012). Taken together, this suggests the optical proper- 

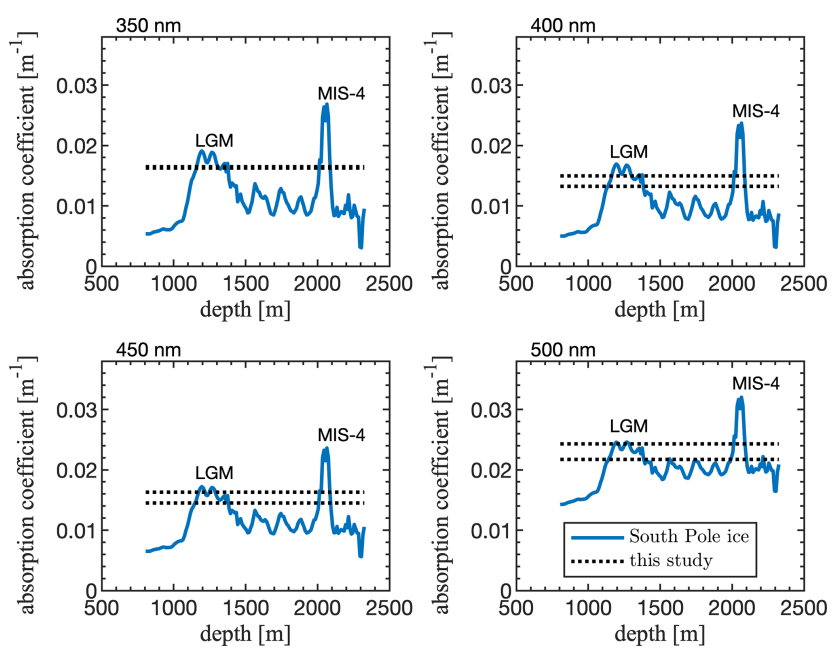

Figure 11. Depth profiles of South Pole ice absorption coefficient at four wavelengths obtained from Eq. (26) and Table 3 of Ackermann et al. (2006). The $1 \% \mathrm{~K}^{-1}$ temperature dependence of pure-ice absorptivity (Woschnagg and Price, 2001) is removed from South Pole values for comparison with this study's lower (Layer B) and upper (Layer A) absorption coefficient estimate at each wavelength (dashed lines). Values reported in this study are consistent with South Pole values at depths corresponding to the Last Glacial Maximum and Marine Isotope Stage 4 when atmospheric-dust concentrations peaked in both hemispheres. Note that South Pole age and dust concentration do not map to ice near the Greenland Ice Sheet margin. Rather, Southern Hemisphere dust concentrations during the LGM and MIS-4 are consistent with Northern Hemisphere dust concentrations during warm interglacial periods and/or periods with low aeolian activity (Muhs, 2013; Reeh et al., 2002).

ties documented here are representative of Pleistocene interglacial ice with relatively low volumetric LAP concentration and smaller crystal diameters than Holocene ice associated with the "dark zone" further inland (Gow et al., 1997; Petrenko et al., 2006; Wientjes et al., 2011).

Regarding pure-ice absorptivity, our $k_{\mathrm{abs}}$ values provide support for the lower-bound pure-ice estimate from Warren et al. (2006) (Fig. 12). The steeply sloping high values in the near UV in the laboratory measurements (Grenfell and Perovich, 1981; Perovich and Govoni, 1991) are now understood as signatures of Rayleigh scattering on nanoscale defects in the laboratory-grown ice (Price and Bergström, 1997a). The South Pole values at $1755 \mathrm{~m}$ depth and $830 \mathrm{~m}$ depth are contaminated by trace dust deposited during the Late Pleistocene and Early Holocene, respectively (Ackermann et al., 2006) (Fig. 11). The lowest values reported by Warren et al. (2006) (hereafter W06) were obtained by applying Eq. (7) to measurements of transmitted radiance in a single snow layer at $\sim 90-135 \mathrm{~cm}$ depth near Dome $\mathrm{C}$ in Antarctica contaminated by $\sim 0.6 \mathrm{ppb}$ of black carbon $\left(75^{\circ} \mathrm{S}, 123^{\circ} \mathrm{E} ; 3230 \mathrm{~m}\right.$ above sea level). Picard et al. (2016) (hereafter P16) repeated the W06 experiment on 56 transmitted radiance profiles collected in snow near Dome $\mathrm{C}$ with variable impurity content.

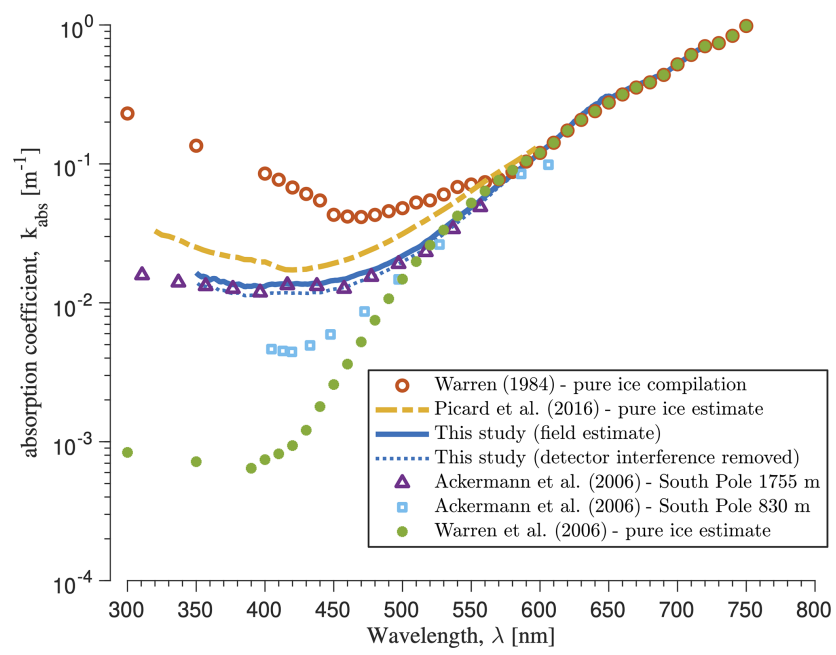

Figure 12. Estimates of ice absorption coefficient $k_{\text {abs }}$, obtained from five distinct sources: laboratory-grown pure ice (Grenfell and Perovich, 1981; Perovich and Govoni, 1991), as compiled in Warren (1984); snow in Antarctica, contaminated by trace concentrations of light-absorbing particles (LAPs) (Picard et al., 2016); glacial ice in Greenland with unknown concentration of LAPs (this study); compressed glacial ice at $1755 \mathrm{~m}$ depth and $830 \mathrm{~m}$ depth in the Antarctic Ice Sheet contaminated by dust deposited during the Late Pleistocene and Early Holocene, respectively (Ackermann et al., 2006); and snow in Antarctica with the effect of LAPs removed (pure-ice estimate) (Warren et al., 2006). Values from this study with the detector interference subtracted are shown as dotted blue line.

The values shown in Fig. 12 are their best estimate of pureice absorptivity from radiance profiles collected in snow with low impurity content (see "clean" subset, Fig. 17 of that paper). P16 were unable to reconcile their values with W06, after considering published values for impurity loadings in the vicinity of Dome C, suggesting the W06 values were unreasonably low. Regardless of that discrepancy, our values were undoubtedly influenced by LAPs but are lower than the P16 values. Treating our Monte Carlo estimate of detector interference as a known systematic error would bring our values closer to the AMANDA and W06 values and further from the P16 values (see dotted line, Fig. 12).

Our absorption minimum is at $390 \mathrm{~nm}$ for Layer A values and $397 \mathrm{~nm}$ for Layer B values, in agreement with W06 and AMANDA. The wavelength shift in the P16 absorption minimum $(430 \mathrm{~nm})$ is coincident with our maximum in transmittance. A similar shift is apparent in all attenuation coefficient spectra shown in Fig. 10 that report the surface as a reference horizon but is absent in those that report an interior reference horizon. P16 used an interior reference horizon, excluding radiance measurements within $8 \mathrm{~cm}$ of the surface based on Monte Carlo simulations of detector interference and visual inspection of homogeneous attenuation zones, but their shifted minimum may indicate that radiance profiles in the near-UV and blue spectra were impacted disproportionately 
by detector rod interference and/or other near-surface effects. The same effects may explain the spectral structure in our near-surface $(0-12 \mathrm{~cm})$ effective attenuation coefficient profile between $350-400 \mathrm{~nm}$ and its broad minimum between 430-490 nm (dotted line, Fig. 10). Similar spectral structure is apparent in diffuse attenuation coefficients obtained in snowpack in the French Alps using the P16 method (cf. Fig. 3b in Tuzet et al., 2019). Differences aside, our inferred absorption spectrum provides new insight into the magnitude of this fundamental but uncertain optical property and supports a conclusion that the minimum is likely $<10^{-2} \mathrm{~m}^{-1}$ and possibly lower (Ackermann et al., 2006; Picard et al., 2016; Warren et al., 2006).

In addition to the traditional concept of surface melt, visible light transmission provides an energy source for subsurface heating and internal melting of near-surface glacier ice (Cooper et al., 2018; Hoffman et al., 2014; Liston and Winther, 2005; Schuster, 2001). Prior estimates of subsurface meltwater production in bare ice used two-stream theory forced with values of $k_{\mathrm{abs}}^{\text {ice }}$ to calculate $k_{\text {att }}$ and the absorbed solar flux as a function of depth below the ice surface in both Greenland and Antarctica (van den Broeke et al., 2008; Hoffman et al., 2014; Kuipers Munneke et al., 2009; Liston and Winther, 2005). The influence of LAPs on subsurface meltwater production has not been quantified to our knowledge and is beyond our scope, but our results suggest LAPs enhance subsurface energy absorption in ablating glacier ice, consistent with enhanced surface melt rates caused by LAPs distributed on bare-ice surfaces and within snowpack (Bøggild et al., 1996; Goelles et al., 2015; Goelles and Bøggild, 2017; Tuzet et al., 2019). From a practical perspective, this suggests that $k_{\text {abs }}$ values for contaminated ice given here and snowpack elsewhere (Picard et al., 2016) could provide realistic input for radiative transfer models absent explicit knowledge of realistic LAP concentrations. In contrast, simulations that use the canonical $k_{\mathrm{abs}}^{\mathrm{ice}}$ values compiled in Warren and Brandt (2008) will likely underestimate light attenuation and misrepresent the distribution of subsurface absorbed flux unless LAP concentrations are otherwise accounted for.

\section{Conclusion}

We report the first in situ spectral measurements of near-UV and visible light transmission in near-surface bare glacial ice, collected at a field site in the western Greenland ablation zone on 20-21 July 2018. In general, our empirical irradiance attenuation coefficients are nearly 1 order of magnitude larger in the range of 350-530 $\mathrm{nm}$ than predicted by asymptotic two-stream theory using canonical values for the absorption coefficient of pure ice (Warren and Brandt, 2008). The absorption minimum is $0.013-0.014 \pm 0.003 \mathrm{~m}^{-1}$ at 390-397 nm, implying absorption length scales of 69-77 m. The volumetric scattering coefficient is $1.6 \pm 0.2 \mathrm{~m}^{-1}$ at $532 \mathrm{~nm}$, with an asymptotic attenuation length scale of $0.62 \pm 0.08 \mathrm{~m}$. In addition to light scattering on air bubbles, we find that light attenuation is enhanced by a layer of quasigranular white ice (weathering crust) that extends from the surface to $\sim 10 \mathrm{~cm}$ depth at our field site. The effective penetration depth, which accounts for reduced optical transmission through this granular layer relative to deeper bubbly ice, is $0.52 \pm 0.07 \mathrm{~m}$ at $532 \mathrm{~nm}$. Our co-located measurements of transmittance and albedo suggest that about $34 \%$ of cloudy sky downwelling solar irradiance at 350-700 nm was absorbed within this upper $10 \mathrm{~cm}$ surface layer at this time and location, consistent with observations of the semi-granular surface layer on sea ice. The estimated absorption spectrum suggests equivalent black carbon and mineral dust concentrations consistent with pre-industrial and warm interglacial periods with low Northern Hemisphere aeolian activity, and therefore it may provide a reasonable lower bound on volumetric absorption enhancement due to impurities embedded in outcropping glacial ice in the western Greenland ablation zone. 


\section{Appendix A}

Table A1. Continued.

Table A1. Estimates of attenuation coefficient and absorption coefficient obtained from solar irradiance transmission measurements in glacier ice (Layer B; 53-124 cm below the ice sheet surface), 1 standard error in the linear regression, and coefficient of determination.

\begin{tabular}{|c|c|c|c|c|c|}
\hline $\begin{array}{l}\text { Wavelength } \\
(\mathrm{nm})\end{array}$ & $\begin{array}{r}k_{\mathrm{att}} \\
\left(\mathrm{m}^{-1}\right)\end{array}$ & $\begin{array}{r}\text { Standard } \\
\text { error } \\
\left(k_{\text {att }}\right)\end{array}$ & $r^{2}$ & $\begin{array}{r}k_{\mathrm{abs}} \\
\left(\mathrm{m}^{-1}\right)\end{array}$ & $\begin{array}{r}\text { Standard } \\
\text { error } \\
\left(k_{\text {abs }}\right)\end{array}$ \\
\hline 350 & 0.975 & 0.021 & 0.999 & 0.0162 & 0.00035 \\
\hline 351 & 0.970 & 0.022 & 0.999 & 0.0160 & 0.00037 \\
\hline 352 & 0.965 & 0.023 & 0.999 & 0.0159 & 0.00038 \\
\hline 353 & 0.960 & 0.024 & 0.999 & 0.0157 & 0.00039 \\
\hline 354 & 0.955 & 0.025 & 0.999 & 0.0155 & 0.00040 \\
\hline 355 & 0.951 & 0.025 & 0.997 & 0.0154 & 0.00041 \\
\hline 356 & 0.947 & 0.026 & 0.998 & 0.0153 & 0.00042 \\
\hline 357 & 0.943 & 0.027 & 0.999 & 0.0152 & 0.00043 \\
\hline 358 & 0.940 & 0.026 & 0.999 & 0.0150 & 0.00041 \\
\hline 359 & 0.936 & 0.026 & 0.999 & 0.0149 & 0.00041 \\
\hline 360 & 0.935 & 0.026 & 0.997 & 0.0149 & 0.00041 \\
\hline 361 & 0.933 & 0.027 & 0.998 & 0.0148 & 0.00042 \\
\hline 362 & 0.931 & 0.029 & 0.999 & 0.0148 & 0.00046 \\
\hline 363 & 0.931 & 0.030 & 0.997 & 0.0148 & 0.00048 \\
\hline 364 & 0.931 & 0.031 & 0.997 & 0.0148 & 0.00049 \\
\hline 365 & 0.927 & 0.031 & 0.998 & 0.0147 & 0.00049 \\
\hline 366 & 0.923 & 0.031 & 0.997 & 0.0145 & 0.00048 \\
\hline 367 & 0.919 & 0.032 & 0.998 & 0.0144 & 0.00050 \\
\hline 368 & 0.915 & 0.031 & 0.997 & 0.0143 & 0.00049 \\
\hline 369 & 0.912 & 0.030 & 0.998 & 0.0142 & 0.00046 \\
\hline 370 & 0.909 & 0.029 & 0.998 & 0.0141 & 0.00045 \\
\hline 371 & 0.908 & 0.029 & 0.998 & 0.0140 & 0.00045 \\
\hline 372 & 0.905 & 0.030 & 0.997 & 0.0140 & 0.00047 \\
\hline 373 & 0.901 & 0.031 & 0.999 & 0.0138 & 0.00048 \\
\hline 374 & 0.897 & 0.033 & 0.998 & 0.0137 & 0.00050 \\
\hline 375 & 0.894 & 0.034 & 0.996 & 0.0136 & 0.00052 \\
\hline 376 & 0.892 & 0.035 & 0.996 & 0.0136 & 0.00053 \\
\hline 377 & 0.892 & 0.035 & 0.997 & 0.0136 & 0.00053 \\
\hline 378 & 0.892 & 0.038 & 0.996 & 0.0136 & 0.00057 \\
\hline 379 & 0.893 & 0.039 & 0.996 & 0.0136 & 0.00060 \\
\hline 380 & 0.892 & 0.040 & 0.997 & 0.0135 & 0.00061 \\
\hline 381 & 0.892 & 0.042 & 0.997 & 0.0136 & 0.00064 \\
\hline 382 & 0.890 & 0.044 & 0.994 & 0.0135 & 0.00067 \\
\hline 383 & 0.886 & 0.045 & 0.993 & 0.0134 & 0.00069 \\
\hline 384 & 0.883 & 0.046 & 0.995 & 0.0133 & 0.00070 \\
\hline 385 & 0.880 & 0.047 & 0.994 & 0.0132 & 0.00070 \\
\hline 386 & 0.878 & 0.046 & 0.995 & 0.0131 & 0.00069 \\
\hline 387 & 0.876 & 0.045 & 0.995 & 0.0131 & 0.00067 \\
\hline 388 & 0.876 & 0.044 & 0.995 & 0.0131 & 0.00066 \\
\hline 389 & 0.879 & 0.046 & 0.995 & 0.0132 & 0.00069 \\
\hline 390 & 0.881 & 0.047 & 0.995 & 0.0132 & 0.00071 \\
\hline 391 & 0.880 & 0.048 & 0.994 & 0.0132 & 0.00073 \\
\hline 392 & 0.881 & 0.050 & 0.993 & 0.0132 & 0.00076 \\
\hline 393 & 0.881 & 0.052 & 0.992 & 0.0132 & 0.00078 \\
\hline 394 & 0.880 & 0.054 & 0.993 & 0.0132 & 0.00081 \\
\hline
\end{tabular}

\begin{tabular}{|c|c|c|c|c|c|}
\hline $\begin{array}{l}\text { Wavelength } \\
(\mathrm{nm})\end{array}$ & $\begin{array}{r}k_{\text {att }} \\
\left(\mathrm{m}^{-1}\right)\end{array}$ & $\begin{array}{r}\text { Standard } \\
\text { error } \\
\left(k_{\text {att }}\right)\end{array}$ & $r^{2}$ & $\begin{array}{r}k_{\mathrm{abs}} \\
\left(\mathrm{m}^{-1}\right)\end{array}$ & $\begin{array}{r}\text { Standard } \\
\text { error } \\
\left(k_{\text {abs }}\right)\end{array}$ \\
\hline 395 & 0.878 & 0.055 & 0.992 & 0.0131 & 0.00082 \\
\hline 396 & 0.877 & 0.056 & 0.991 & 0.0131 & 0.00083 \\
\hline 397 & 0.875 & 0.056 & 0.991 & 0.0131 & 0.00084 \\
\hline 398 & 0.875 & 0.057 & 0.992 & 0.0130 & 0.00085 \\
\hline 399 & 0.877 & 0.059 & 0.992 & 0.0131 & 0.00088 \\
\hline 400 & 0.881 & 0.060 & 0.991 & 0.0132 & 0.00091 \\
\hline 401 & 0.883 & 0.062 & 0.990 & 0.0133 & 0.00093 \\
\hline 402 & 0.886 & 0.064 & 0.990 & 0.0134 & 0.00096 \\
\hline 403 & 0.890 & 0.066 & 0.988 & 0.0135 & 0.00100 \\
\hline 404 & 0.892 & 0.067 & 0.988 & 0.0136 & 0.00102 \\
\hline 405 & 0.892 & 0.068 & 0.988 & 0.0136 & 0.00104 \\
\hline 406 & 0.893 & 0.069 & 0.988 & 0.0136 & 0.00105 \\
\hline 407 & 0.894 & 0.070 & 0.989 & 0.0136 & 0.00107 \\
\hline 408 & 0.894 & 0.071 & 0.988 & 0.0136 & 0.00108 \\
\hline 409 & 0.893 & 0.072 & 0.987 & 0.0136 & 0.00110 \\
\hline 410 & 0.894 & 0.074 & 0.987 & 0.0136 & 0.00112 \\
\hline 411 & 0.895 & 0.075 & 0.986 & 0.0136 & 0.00114 \\
\hline 412 & 0.896 & 0.075 & 0.986 & 0.0137 & 0.00115 \\
\hline 413 & 0.897 & 0.076 & 0.985 & 0.0137 & 0.00116 \\
\hline 414 & 0.897 & 0.076 & 0.985 & 0.0137 & 0.00117 \\
\hline 415 & 0.897 & 0.077 & 0.987 & 0.0137 & 0.00118 \\
\hline 416 & 0.896 & 0.077 & 0.987 & 0.0137 & 0.00118 \\
\hline 417 & 0.896 & 0.078 & 0.984 & 0.0137 & 0.00119 \\
\hline 418 & 0.896 & 0.079 & 0.983 & 0.0137 & 0.00120 \\
\hline 419 & 0.895 & 0.080 & 0.985 & 0.0137 & 0.00122 \\
\hline 420 & 0.896 & 0.081 & 0.984 & 0.0137 & 0.00124 \\
\hline 421 & 0.896 & 0.082 & 0.984 & 0.0137 & 0.00125 \\
\hline 422 & 0.897 & 0.082 & 0.983 & 0.0137 & 0.00125 \\
\hline 423 & 0.897 & 0.082 & 0.983 & 0.0137 & 0.00126 \\
\hline 424 & 0.897 & 0.083 & 0.983 & 0.0137 & 0.00127 \\
\hline 425 & 0.896 & 0.084 & 0.984 & 0.0137 & 0.00128 \\
\hline 426 & 0.896 & 0.084 & 0.982 & 0.0137 & 0.00129 \\
\hline 427 & 0.895 & 0.085 & 0.982 & 0.0137 & 0.00130 \\
\hline 428 & 0.894 & 0.085 & 0.983 & 0.0136 & 0.00130 \\
\hline 429 & 0.893 & 0.086 & 0.982 & 0.0136 & 0.00131 \\
\hline 430 & 0.894 & 0.088 & 0.980 & 0.0136 & 0.00133 \\
\hline 431 & 0.895 & 0.088 & 0.982 & 0.0137 & 0.00134 \\
\hline 432 & 0.896 & 0.089 & 0.981 & 0.0137 & 0.00135 \\
\hline 433 & 0.897 & 0.090 & 0.979 & 0.0137 & 0.00137 \\
\hline 434 & 0.898 & 0.091 & 0.980 & 0.0137 & 0.00139 \\
\hline 435 & 0.899 & 0.091 & 0.981 & 0.0138 & 0.00140 \\
\hline 436 & 0.900 & 0.092 & 0.980 & 0.0138 & 0.00141 \\
\hline 437 & 0.900 & 0.093 & 0.978 & 0.0138 & 0.00142 \\
\hline 438 & 0.899 & 0.093 & 0.979 & 0.0138 & 0.00142 \\
\hline 439 & 0.899 & 0.093 & 0.979 & 0.0138 & 0.00142 \\
\hline 440 & 0.899 & 0.093 & 0.979 & 0.0138 & 0.00143 \\
\hline 441 & 0.900 & 0.093 & 0.980 & 0.0138 & 0.00142 \\
\hline 442 & 0.901 & 0.093 & 0.979 & 0.0138 & 0.00143 \\
\hline 443 & 0.904 & 0.093 & 0.979 & 0.0139 & 0.00144 \\
\hline 444 & 0.907 & 0.094 & 0.979 & 0.0140 & 0.00146 \\
\hline 445 & 0.910 & 0.095 & 0.979 & 0.0141 & 0.00148 \\
\hline 446 & 0.913 & 0.096 & 0.978 & 0.0142 & 0.00150 \\
\hline 447 & 0.916 & 0.097 & 0.978 & 0.0143 & 0.00152 \\
\hline
\end{tabular}


Table A1. Continued.

\begin{tabular}{|c|c|c|c|c|c|}
\hline $\begin{array}{l}\text { Wavelength } \\
(\mathrm{nm})\end{array}$ & $\begin{array}{r}k_{\mathrm{att}} \\
\left(\mathrm{m}^{-1}\right)\end{array}$ & $\begin{array}{r}\text { Standard } \\
\text { error } \\
\left(k_{\mathrm{att}}\right)\end{array}$ & $r^{2}$ & $\begin{array}{r}k_{\mathrm{abs}} \\
\left(\mathrm{m}^{-1}\right)\end{array}$ & $\begin{array}{r}\text { Standard } \\
\text { error } \\
\left(k_{\mathrm{abs}}\right)\end{array}$ \\
\hline 448 & 0.918 & 0.098 & 0.978 & 0.0144 & 0.00153 \\
\hline 449 & 0.920 & 0.099 & 0.977 & 0.0144 & 0.00155 \\
\hline 450 & 0.922 & 0.099 & 0.977 & 0.0145 & 0.00155 \\
\hline 451 & 0.922 & 0.099 & 0.978 & 0.0145 & 0.00155 \\
\hline 452 & 0.923 & 0.099 & 0.978 & 0.0145 & 0.00156 \\
\hline 453 & 0.925 & 0.099 & 0.977 & 0.0146 & 0.00157 \\
\hline 454 & 0.926 & 0.100 & 0.978 & 0.0146 & 0.00157 \\
\hline 455 & 0.927 & 0.100 & 0.977 & 0.0146 & 0.00158 \\
\hline 456 & 0.929 & 0.100 & 0.976 & 0.0147 & 0.00158 \\
\hline 457 & 0.931 & 0.100 & 0.977 & 0.0148 & 0.00158 \\
\hline 458 & 0.933 & 0.100 & 0.978 & 0.0148 & 0.00159 \\
\hline 459 & 0.936 & 0.101 & 0.978 & 0.0149 & 0.00161 \\
\hline 460 & 0.939 & 0.101 & 0.978 & 0.0150 & 0.00162 \\
\hline 461 & 0.942 & 0.102 & 0.977 & 0.0151 & 0.00164 \\
\hline 462 & 0.946 & 0.103 & 0.975 & 0.0153 & 0.00166 \\
\hline 463 & 0.951 & 0.104 & 0.976 & 0.0154 & 0.00169 \\
\hline 464 & 0.955 & 0.105 & 0.976 & 0.0155 & 0.00171 \\
\hline 465 & 0.960 & 0.105 & 0.977 & 0.0157 & 0.00172 \\
\hline 466 & 0.964 & 0.105 & 0.977 & 0.0158 & 0.00172 \\
\hline 467 & 0.968 & 0.105 & 0.977 & 0.0160 & 0.00173 \\
\hline 468 & 0.972 & 0.105 & 0.977 & 0.0161 & 0.00174 \\
\hline 469 & 0.975 & 0.105 & 0.977 & 0.0162 & 0.00175 \\
\hline 470 & 0.979 & 0.106 & 0.977 & 0.0163 & 0.00177 \\
\hline 471 & 0.981 & 0.107 & 0.977 & 0.0164 & 0.00178 \\
\hline 472 & 0.984 & 0.107 & 0.977 & 0.0165 & 0.00180 \\
\hline 473 & 0.987 & 0.107 & 0.976 & 0.0166 & 0.00181 \\
\hline 474 & 0.991 & 0.107 & 0.976 & 0.0167 & 0.00181 \\
\hline 475 & 0.994 & 0.107 & 0.977 & 0.0168 & 0.00182 \\
\hline 476 & 0.997 & 0.107 & 0.978 & 0.0169 & 0.00182 \\
\hline 477 & 1.001 & 0.107 & 0.978 & 0.0171 & 0.00183 \\
\hline 478 & 1.004 & 0.107 & 0.977 & 0.0172 & 0.00183 \\
\hline 479 & 1.008 & 0.107 & 0.978 & 0.0173 & 0.00184 \\
\hline 480 & 1.012 & 0.107 & 0.978 & 0.0175 & 0.00185 \\
\hline 481 & 1.016 & 0.107 & 0.978 & 0.0176 & 0.00186 \\
\hline 482 & 1.021 & 0.107 & 0.978 & 0.0178 & 0.00187 \\
\hline 483 & 1.026 & 0.108 & 0.978 & 0.0179 & 0.00188 \\
\hline 484 & 1.031 & 0.108 & 0.979 & 0.0181 & 0.00189 \\
\hline 485 & 1.037 & 0.108 & 0.979 & 0.0183 & 0.00190 \\
\hline 486 & 1.042 & 0.107 & 0.979 & 0.0185 & 0.00191 \\
\hline 487 & 1.048 & 0.107 & 0.979 & 0.0187 & 0.00192 \\
\hline 488 & 1.053 & 0.107 & 0.980 & 0.0189 & 0.00192 \\
\hline 489 & 1.058 & 0.107 & 0.980 & 0.0191 & 0.00193 \\
\hline 490 & 1.064 & 0.107 & 0.980 & 0.0193 & 0.00194 \\
\hline 491 & 1.069 & 0.107 & 0.980 & 0.0195 & 0.00195 \\
\hline 492 & 1.075 & 0.107 & 0.981 & 0.0197 & 0.00196 \\
\hline 493 & 1.081 & 0.107 & 0.980 & 0.0199 & 0.00198 \\
\hline 494 & 1.087 & 0.107 & 0.981 & 0.0202 & 0.00199 \\
\hline 495 & 1.094 & 0.108 & 0.981 & 0.0204 & 0.00201 \\
\hline 496 & 1.101 & 0.108 & 0.981 & 0.0207 & 0.00203 \\
\hline 497 & 1.108 & 0.108 & 0.982 & 0.0209 & 0.00204 \\
\hline 498 & 1.115 & 0.108 & 0.981 & 0.0212 & 0.00205 \\
\hline 499 & 1.123 & 0.108 & 0.981 & 0.0215 & 0.00207 \\
\hline 500 & 1.130 & 0.108 & 0.982 & 0.0218 & 0.00208 \\
\hline
\end{tabular}

Table A1. Continued.

\begin{tabular}{|c|c|c|c|c|c|}
\hline $\begin{array}{l}\text { Wavelength } \\
(\mathrm{nm})\end{array}$ & $\begin{array}{r}k_{\mathrm{att}} \\
\left(\mathrm{m}^{-1}\right)\end{array}$ & $\begin{array}{r}\text { Standard } \\
\text { error } \\
\left(k_{\mathrm{att}}\right)\end{array}$ & $r^{2}$ & $\begin{array}{r}k_{\mathrm{abs}} \\
\left(\mathrm{m}^{-1}\right)\end{array}$ & $\begin{array}{r}\text { Standard } \\
\text { error } \\
\left(k_{\mathrm{abs}}\right)\end{array}$ \\
\hline 501 & 1.138 & 0.108 & 0.983 & 0.0221 & 0.00209 \\
\hline 502 & 1.145 & 0.108 & 0.982 & 0.0223 & 0.00210 \\
\hline 503 & 1.152 & 0.107 & 0.983 & 0.0226 & 0.00211 \\
\hline 504 & 1.159 & 0.107 & 0.983 & 0.0229 & 0.00212 \\
\hline 505 & 1.167 & 0.108 & 0.983 & 0.0232 & 0.00214 \\
\hline 506 & 1.174 & 0.108 & 0.983 & 0.0235 & 0.00216 \\
\hline 507 & 1.181 & 0.108 & 0.983 & 0.0238 & 0.00218 \\
\hline 508 & 1.188 & 0.108 & 0.984 & 0.0240 & 0.00220 \\
\hline 509 & 1.195 & 0.109 & 0.984 & 0.0243 & 0.00222 \\
\hline 510 & 1.202 & 0.109 & 0.983 & 0.0246 & 0.00223 \\
\hline 511 & 1.209 & 0.109 & 0.984 & 0.0249 & 0.00224 \\
\hline 512 & 1.216 & 0.109 & 0.984 & 0.0252 & 0.00225 \\
\hline 513 & 1.226 & 0.109 & 0.984 & 0.0256 & 0.00227 \\
\hline 514 & 1.237 & 0.108 & 0.985 & 0.0261 & 0.00228 \\
\hline 515 & 1.248 & 0.108 & 0.985 & 0.0265 & 0.00229 \\
\hline 516 & 1.259 & 0.108 & 0.986 & 0.0270 & 0.00231 \\
\hline 517 & 1.269 & 0.108 & 0.986 & 0.0274 & 0.00233 \\
\hline 518 & 1.279 & 0.108 & 0.986 & 0.0279 & 0.00234 \\
\hline 519 & 1.290 & 0.108 & 0.986 & 0.0283 & 0.00236 \\
\hline 520 & 1.300 & 0.108 & 0.986 & 0.0288 & 0.00238 \\
\hline 521 & 1.310 & 0.107 & 0.987 & 0.0292 & 0.00240 \\
\hline 522 & 1.320 & 0.107 & 0.987 & 0.0297 & 0.00241 \\
\hline 523 & 1.333 & 0.107 & 0.987 & 0.0303 & 0.00242 \\
\hline 524 & 1.345 & 0.106 & 0.988 & 0.0308 & 0.00243 \\
\hline 525 & 1.358 & 0.105 & 0.988 & 0.0314 & 0.00244 \\
\hline 526 & 1.370 & 0.105 & 0.988 & 0.0320 & 0.00245 \\
\hline 527 & 1.382 & 0.104 & 0.989 & 0.0326 & 0.00246 \\
\hline 528 & 1.394 & 0.104 & 0.989 & 0.0331 & 0.00247 \\
\hline 529 & 1.407 & 0.104 & 0.989 & 0.0337 & 0.00248 \\
\hline 530 & 1.419 & 0.104 & 0.989 & 0.0343 & 0.00250 \\
\hline 531 & 1.432 & 0.103 & 0.990 & 0.0349 & 0.00252 \\
\hline 532 & 1.445 & 0.104 & 0.990 & 0.0356 & 0.00255 \\
\hline 533 & 1.458 & 0.104 & 0.990 & 0.0362 & 0.00258 \\
\hline 534 & 1.471 & 0.103 & 0.990 & 0.0369 & 0.00259 \\
\hline 535 & 1.483 & 0.103 & 0.990 & 0.0375 & 0.00260 \\
\hline 536 & 1.497 & 0.103 & 0.990 & 0.0382 & 0.00262 \\
\hline 537 & 1.511 & 0.102 & 0.991 & 0.0389 & 0.00264 \\
\hline 538 & 1.525 & 0.102 & 0.991 & 0.0396 & 0.00266 \\
\hline 539 & 1.539 & 0.102 & 0.991 & 0.0404 & 0.00268 \\
\hline 540 & 1.553 & 0.102 & 0.991 & 0.0411 & 0.00270 \\
\hline 541 & 1.567 & 0.102 & 0.991 & 0.0419 & 0.00273 \\
\hline 542 & 1.581 & 0.102 & 0.992 & 0.0426 & 0.00275 \\
\hline 543 & 1.595 & 0.102 & 0.992 & 0.0433 & 0.00278 \\
\hline 544 & 1.608 & 0.102 & 0.992 & 0.0440 & 0.00280 \\
\hline 545 & 1.621 & 0.102 & 0.992 & 0.0448 & 0.00282 \\
\hline 546 & 1.634 & 0.103 & 0.992 & 0.0455 & 0.00286 \\
\hline 547 & 1.648 & 0.103 & 0.992 & 0.0463 & 0.00290 \\
\hline 548 & 1.662 & 0.104 & 0.992 & 0.0471 & 0.00294 \\
\hline 549 & 1.677 & 0.104 & 0.992 & 0.0479 & 0.00296 \\
\hline 550 & 1.690 & 0.103 & 0.992 & 0.0487 & 0.00298 \\
\hline 551 & 1.704 & 0.103 & 0.993 & 0.0495 & 0.00299 \\
\hline 552 & 1.718 & 0.103 & 0.993 & 0.0503 & 0.00300 \\
\hline 553 & 1.732 & 0.102 & 0.993 & 0.0511 & 0.00301 \\
\hline
\end{tabular}


Table A1. Continued.

\begin{tabular}{|c|c|c|c|c|c|}
\hline $\begin{array}{l}\text { Wavelength } \\
(\mathrm{nm})\end{array}$ & $\begin{array}{r}k_{\mathrm{att}} \\
\left(\mathrm{m}^{-1}\right)\end{array}$ & $\begin{array}{r}\text { Standard } \\
\text { error } \\
\left(k_{\mathrm{att}}\right)\end{array}$ & $r^{2}$ & $\begin{array}{r}k_{\mathrm{abs}} \\
\left(\mathrm{m}^{-1}\right)\end{array}$ & $\begin{array}{r}\text { Standard } \\
\text { error } \\
\left(k_{\mathrm{abs}}\right)\end{array}$ \\
\hline 554 & 1.747 & 0.102 & 0.993 & 0.0520 & 0.00303 \\
\hline 555 & 1.763 & 0.102 & 0.993 & 0.0530 & 0.00306 \\
\hline 556 & 1.780 & 0.102 & 0.993 & 0.0540 & 0.00310 \\
\hline 557 & 1.798 & 0.102 & 0.993 & 0.0551 & 0.00313 \\
\hline 558 & 1.817 & 0.102 & 0.994 & 0.0562 & 0.00316 \\
\hline 559 & 1.835 & 0.102 & 0.994 & 0.0574 & 0.00319 \\
\hline 560 & 1.853 & 0.102 & 0.994 & 0.0585 & 0.00321 \\
\hline 561 & 1.870 & 0.101 & 0.994 & 0.0596 & 0.00322 \\
\hline 562 & 1.888 & 0.101 & 0.994 & 0.0607 & 0.00324 \\
\hline 563 & 1.906 & 0.100 & 0.995 & 0.0619 & 0.00326 \\
\hline 564 & 1.925 & 0.100 & 0.995 & 0.0631 & 0.00328 \\
\hline 565 & 1.944 & 0.099 & 0.995 & 0.0644 & 0.00328 \\
\hline 566 & 1.964 & 0.099 & 0.995 & 0.0657 & 0.00331 \\
\hline 567 & 1.983 & 0.098 & 0.995 & 0.0670 & 0.00333 \\
\hline 568 & 2.001 & 0.098 & 0.995 & 0.0683 & 0.00335 \\
\hline 569 & 2.019 & 0.098 & 0.995 & 0.0695 & 0.00337 \\
\hline 570 & 2.037 & 0.098 & 0.995 & 0.0707 & 0.00338 \\
\hline 571 & 2.055 & 0.097 & 0.995 & 0.0720 & 0.00341 \\
\hline 572 & 2.072 & 0.097 & 0.996 & 0.0732 & 0.00343 \\
\hline 573 & 2.090 & 0.097 & 0.996 & 0.0744 & 0.00347 \\
\hline 574 & 2.108 & 0.098 & 0.996 & 0.0757 & 0.00350 \\
\hline 575 & 2.126 & 0.097 & 0.996 & 0.0770 & 0.00353 \\
\hline 576 & 2.143 & 0.098 & 0.996 & 0.0782 & 0.00357 \\
\hline 577 & 2.160 & 0.098 & 0.996 & 0.0795 & 0.00360 \\
\hline 578 & 2.178 & 0.097 & 0.996 & 0.0808 & 0.00362 \\
\hline 579 & 2.197 & 0.097 & 0.996 & 0.0822 & 0.00364 \\
\hline 580 & 2.216 & 0.097 & 0.996 & 0.0837 & 0.00366 \\
\hline 581 & 2.237 & 0.097 & 0.996 & 0.0853 & 0.00370 \\
\hline 582 & 2.257 & 0.097 & 0.996 & 0.0868 & 0.00373 \\
\hline 583 & 2.276 & 0.097 & 0.996 & 0.0882 & 0.00376 \\
\hline 584 & 2.296 & 0.097 & 0.996 & 0.0898 & 0.00379 \\
\hline 585 & 2.317 & 0.097 & 0.996 & 0.0914 & 0.00382 \\
\hline 586 & 2.337 & 0.097 & 0.997 & 0.0930 & 0.00388 \\
\hline 587 & 2.358 & 0.097 & 0.997 & 0.0947 & 0.00391 \\
\hline 588 & 2.380 & 0.097 & 0.997 & 0.0965 & 0.00393 \\
\hline 589 & 2.402 & 0.097 & 0.997 & 0.0983 & 0.00395 \\
\hline 590 & 2.424 & 0.096 & 0.997 & 0.1001 & 0.00398 \\
\hline 591 & 2.446 & 0.096 & 0.997 & 0.1020 & 0.00400 \\
\hline 592 & 2.468 & 0.096 & 0.997 & 0.1038 & 0.00402 \\
\hline 593 & 2.489 & 0.096 & 0.997 & 0.1055 & 0.00405 \\
\hline 594 & 2.512 & 0.095 & 0.997 & 0.1076 & 0.00407 \\
\hline 595 & 2.536 & 0.095 & 0.997 & 0.1096 & 0.00412 \\
\hline 596 & 2.560 & 0.096 & 0.997 & 0.1116 & 0.00417 \\
\hline 597 & 2.583 & 0.096 & 0.997 & 0.1137 & 0.00421 \\
\hline 598 & 2.606 & 0.096 & 0.997 & 0.1158 & 0.00426 \\
\hline 599 & 2.630 & 0.096 & 0.997 & 0.1179 & 0.00431 \\
\hline 600 & 2.653 & 0.096 & 0.997 & 0.1200 & 0.00435 \\
\hline
\end{tabular}


Code availability. The Monte Carlo model is publicly available at https://doi.org/10.5281/zenodo.4579073 (Cooper, 2021) and can be used to replicate the results presented here.

The data are hosted by the PANGAEA open-access data repository (https://doi.org/10.1594/PANGAEA.930278, Cooper et al., 2021) and are provided in Appendix A.

Supplement. The supplement related to this article is available online at: https://doi.org/10.5194/tc-15-1931-2021-supplement.

Author contributions. MGC and LCS designed the experiment. MGC, AKR, MT, RM, SZL, and SEM collected the field data. MGC performed the data analysis and wrote the manuscript. LCS, AKR, MT, SZL, and JVF edited the manuscript.

Competing interests. The authors declare that they have no conflict of interest.

Acknowledgements. The authors thank Steven G. Warren, Richard E. Brandt, and Ghislain Picard for advice on the experimental design and Robert Leathers and Trijntje Downes for guidance on Monte Carlo radiative transfer methods. The authors thank the handling editor and the two anonymous reviewers for thorough and constructive reviews of the manuscript.

Financial support. This project was funded by the NASA Cryospheric Sciences Program (grant nos. NNX14AH93G and 80NSSC19K0942) managed by Thomas P. Wagner and Thorsten Markus and by a graduate fellowship from the NASA Earth and Space Science Fellowship Program (grant no. 80NSSC17K0374) managed by Lin Chambers. Polar Field Services and Kangerlussuaq International Science Support (KISS) provided field logistical support.

Review statement. This paper was edited by Mark Flanner and reviewed by two anonymous referees.

\section{References}

Ackermann, M., Ahrens, J., Bai, X., Bartelt, M., Barwick, S. W., Bay, R. C., Becka, T., Becker, J. K., Becker, K.-H., Berghaus, P., Bernardini, E., Bertrand, D., Boersma, D. J., Böser, S., Botner, O., Bouchta, A., Bouhali, O., Burgess, C., Burgess, T., Castermans, T., Chirkin, D., Collin, B., Conrad, J., Cooley, J., Cowen, D. F., Davour, A., Clercq, C. D., Heros, C. P. de los, Desiati, P., DeYoung, T., Ekström, P., Feser, T., Gaisser, T. K., Ganugapati, R., Geenen, H., Gerhardt, L., Goldschmidt, A., Groß, A., Hallgren, A., Halzen, F., Hanson, K., Hardtke, D. H., Harenberg, T., Hauschildt, T., Helbing, K., Hellwig, M., Herquet, P., Hill, G. C., Hodges, J., Hubert, D., Hughey, B., Hulth, P. O., Hultqvist, K., Hundertmark, S., Jacobsen, J., Kampert, K. H., Karle, A., Kestel,
M., Kohnen, G., Köpke, L., Kowalski, M., Kuehn, K., Lang, R., Leich, H., Leuthold, M., Liubarsky, I., Lundberg, J., Madsen, J., Marciniewski, P., Matis, H. S., McParland, C. P., Messarius, T., Minaeva, Y., Miočinović, P., Morse, R., Münich, K., Nahnhauer, R., Nam, J. W., Neunhöffer, T., Niessen, P., Nygren, D. R., Olbrechts, P., Pohl, A. C., Porrata, R., Price, P. B., Przybylski, G. T., Rawlins, K., Resconi, E., Rhode, W., Ribordy, M., Richter, S., Martino, J. R., Sander, H.-G., Schlenstedt, S., Schneider, D., Schwarz, R., Silvestri, A., Solarz, M., Spiczak, G. M., Spiering, C., Stamatikos, M., Steele, D., Steffen, P., Stokstad, R.G., Sulanke, K.-H., Taboada, I., Tarasova, O., Thollander, L., Tilav, S., Wagner, W., Walck, C., Walter, M., Wang, Y.-R., Wiebusch, C.H., Wischnewski, R., Wissing, H., and Woschnagg, K.: Optical properties of deep glacial ice at the South Pole, J. Geophys. Res.Atmos., 111, D13203, https://doi.org/10.1029/2005JD006687, 2006.

Askebjer, P., Barwick, S. W., Bergström, L., Bouchta, A., Carius, S., Coulthard, A., Engel, K., Erlandsson, B., Goobar, A., Gray, L., Hallgren, A., Halzen, F., Hulth, P. O., Jacobsen, J., Johansson, S., Kandhadai, V., Liubarsky, I., Lowder, D., Miller, T., Mock, P. C., Morse, R., Porrata, R., Price, P. B., Richards, A., Rubinstein, H., Schneider, E., Sun, Q., Tilav, S., Walck, C., and Yodh, G.: Optical Properties of the South Pole Ice at Depths Between 0.8 and 1 Kilometer, Science, 267, 1147-1150, https://doi.org/10.1126/science.267.5201.1147, 1995.

Askebjer, P., Barwick, S. W., Bergström, L., Bouchta, A., Carius, S., Dalberg, E., Erlandsson, B., Goobar, A., Gray, L., Hallgren, A., Halzen, F., Heukenkamp, H., Hulth, P. O., Hundertmark, S., Jacobsen, J., Kandhadai, V., Karle, A., Liubarsky, I., Lowder, D., Miller, T., Mock, P., Morse, R., Porrata, R., Price, P. B., Richards, A., Rubinstein, H., Schneider, E., Spiering, C., Streicher, O., Sun, Q., Thon, T., Tilav, S., Wischnewski, R., Walck, C., and Yodh, G.: UV and optical light transmission properties in deep ice at the South Pole, Geophys. Res. Lett., 24, 1355-1358, https://doi.org/10.1029/97GL01246, 1997.

Bintanja, R. and Van Den Broeke, M. R.: The Surface Energy Balance of Antarctic Snow and Blue Ice, J. Appl. Meteor., 34, 902-926, https://doi.org/10.1175/15200450(1995)034<0902:TSEBOA>2.0.CO;2, 1995.

Bøggild, C. E., Oerter, H., and Tukiainen, T.: Increased ablation of Wisconsin ice in eastern north Greenland: observations and modelling, Ann. Glaciol., 23, 144-148, https://doi.org/10.3189/S0260305500013367, 1996.

Bøggild, C. E., Brandt, R. E., Brown, K. J. and Warren, S. G.: The ablation zone in northeast Greenland: ice types, albedos and impurities, J. Glaciol., 56, 101-113, https://doi.org/10.3189/002214310791190776, 2010.

Bohren, C. F.: Colors of snow, frozen waterfalls, and icebergs, J. Opt. Soc. Am., J. Opt. Soc. Am., 73, 1646-1652, https://doi.org/10.1364/JOSA.73.001646, 1983.

Bohren, C. F.: Multiple scattering of light and some of its observable consequences, Am. J. Phys., 55, 524-533, https://doi.org/10.1119/1.15109, 1987.

Bohren, C. F. and Barkstrom, B. R.: Theory of the optical properties of snow, J. Geophys. Res., 79, 4527-4535, https://doi.org/10.1029/JC079i030p04527, 1974.

Brandt, R. E. and Warren, S. G.: Solar-heating rates and temperature profiles in Antarctic snow and ice, J. Glaciol., 39, 99-110, https://doi.org/10.3189/S0022143000015756, 1993. 
Briegleb, B. P. and Light, B.: A Delta-Eddington Mutiple Scattering Parameterization for Solar Radiation in the Sea Ice Component of the Community Climate System Model, Technical Note, National Center for Atmospheric Research, Boulder, Colorado, https://doi.org/10.5065/D6B27S71, 2007.

Brunt, K. M., Neumann, T. A., Amundson, J. M., Kavanaugh, J. L., Moussavi, M. S., Walsh, K. M., Cook, W. B., and Markus, T.: MABEL photon-counting laser altimetry data in Alaska for ICESat-2 simulations and development, The Cryosphere, 10, 1707-1719, https://doi.org/10.5194/tc-10-1707-2016, 2016.

Cantrell, C. A.: Technical Note: Review of methods for linear least-squares fitting of data and application to atmospheric chemistry problems, Atmos. Chem. Phys., 8, 5477-5487, https://doi.org/10.5194/acp-8-5477-2008, 2008.

Cooper, M. G.: Ice Monte Carlo Radiative Transfer Model v1.0 (Version v1.0), Zenodo, https://doi.org/10.5281/zenodo.4579073, 2021.

Cooper, M. G., Smith, L. C., Rennermalm, A. K., Miège, C., Pitcher, L. H., Ryan, J. C., Yang, K., and Cooley, S. W.: Meltwater storage in low-density near-surface bare ice in the Greenland ice sheet ablation zone, The Cryosphere, 12, 955-970, https://doi.org/10.5194/tc-12-955-2018, 2018.

Cooper, M. G., Smith, L. C., Rennermalm, A. K., Tedesco, M., Muthyala, R., Leidman, S. Z., Moustafa, S. E., and Fayne, J. V.: Optical attenuation coefficients of glacier ice from 350$700 \mathrm{~nm}$ and raw irradiance values from $350-900 \mathrm{~nm}$, PANGAEA, https://doi.org/10.1594/PANGAEA.930278, 2021.

Dadic, R., Mullen, P. C., Schneebeli, M., Brandt, R. E., and Warren, S. G.: Effects of bubbles, cracks, and volcanic tephra on the spectral albedo of bare ice near the Transantarctic Mountains: Implications for sea glaciers on Snowball Earth, J. Geophys. Res.Earth Surf., 118, 1658-1676, https://doi.org/10.1002/jgrf.20098, 2013.

Deems, J. S., Painter, T. H., and Finnegan, D. C.: Lidar measurement of snow depth: a review, J. Glaciol., 59, 467-479, https://doi.org/10.3189/2013JoG12J154, 2013.

Di Mauro, B., Baccolo, G., Garzonio, R., Giardino, C., Massabò, D., Piazzalunga, A., Rossini, M., and Colombo, R.: Impact of impurities and cryoconite on the optical properties of the Morteratsch Glacier (Swiss Alps), The Cryosphere, 11, 2393-2409, https://doi.org/10.5194/tc-11-2393-2017, 2017.

Doherty, S. J., Warren, S. G., Grenfell, T. C., Clarke, A. D., and Brandt, R. E.: Light-absorbing impurities in Arctic snow, Atmos. Chem. Phys., 10, 11647-11680, https://doi.org/10.5194/acp-1011647-2010, 2010.

Fisher, F. N., King, M. D., and Lee-Taylor, J.: Extinction of UVvisible radiation in wet midlatitude (maritime) snow: Implications for increased $\mathrm{NO}_{x}$ emission, J. Geophys. Res., 110, D21301, https://doi.org/10.1029/2005JD005963, 2005.

France, J. L., King, M. D., Frey, M. M., Erbland, J., Picard, G., Preunkert, S., MacArthur, A., and Savarino, J.: Snow optical properties at Dome C (Concordia), Antarctica; implications for snow emissions and snow chemistry of reactive nitrogen, Atmos. Chem. Phys., 11, 9787-9801, https://doi.org/10.5194/acp11-9787-2011, 2011.

Frey, K. E., Perovich, D. K., and Light, B.: The spatial distribution of solar radiation under a melting Arctic sea ice cover, Geophys. Res. Lett., 38, L22501, https://doi.org/10.1029/2011GL049421, 2011.
Gardner, A. S. and Sharp, M. J.: A review of snow and ice albedo and the development of a new physically based broadband albedo parameterization, J. Geophys. Res., 115, F01009, https://doi.org/10.1029/2009JF001444, 2010.

Gardner, A. S., Smith, B. E., Brunt, K. M., Harding, D. J., Neumann, T., and Walsh, K.: ICESat2 subsurface-scattering biases estimated based on the 2015 SIMPL/AVRIS campaign, in AGU Fall Meeting Abstracts, vol. 41, C41C-0710, http://adsabs. harvard.edu/abs/2015AGUFM.C41C0710G (last access: 25 January 2019), 2015.

Gerland, S., Liston, G. E., Winther, J.-G., Ørbæk, J. B., and Ivanov, B. V.: Attenuation of solar radiation in Arctic snow: field observations and modelling, Ann. Glaciol., 31, 364-368, https://doi.org/10.3189/172756400781820444, 2000.

Goelles, T. and Bøggild, C. E.: Albedo reduction of ice caused by dust and black carbon accumulation: a model applied to the K-transect, West Greenland, J. Glaciol., 63, 1063-1076, https://doi.org/10.1017/jog.2017.74, 2017.

Goelles, T., Bøggild, C. E., and Greve, R.: Ice sheet mass loss caused by dust and black carbon accumulation, The Cryosphere, 9, 1845-1856, https://doi.org/10.5194/tc-9-1845-2015, 2015.

Gow, A. J., Meese, D. A., Alley, R. B., Fitzpatrick, J. J., Anandakrishnan, S., Woods, G. A., and Elder, B. C.: Physical and structural properties of the Greenland Ice Sheet Project 2 ice core: A review, J. Geophys. Res., 102, 26559-26575, https://doi.org/10.1029/97JC00165, 1997.

Greeley, A., Kurtz, N. T., Neumann, T., and Markus, T.: Estimating Surface Elevation Bias Due to Subsurface Scattered Photons from Visible Wavelength Laser Altimeters, in AGU Fall Meeting Abstracts, vol. 51, http://adsabs.harvard.edu/abs/2017AGUFM. C51A0961G (last access: 25 January 2019), 2017.

Grenfell, T. C.: The Effects of Ice Thickness on the Exchange of Solar Radiation Over the Polar Oceans, J. Glaciol., 22, 305-320, https://doi.org/10.3189/S0022143000014295, 1979.

Grenfell, T. C.: A radiative transfer model for sea ice with vertical structure variations, J. Geophys. Res.-Oceans, 96, 16991-17001, https://doi.org/10.1029/91JC01595, 1991.

Grenfell, T. C. and Maykut, G. A.: The Optical Properties of Ice and Snow in the Arctic Basin, J. Glaciol., 18, 445-463, https://doi.org/10.3189/S0022143000021122, 1977.

Grenfell, T. C. and Perovich, D. K.: Radiation absorption coefficients of polycrystalline ice from 400-1400 nm, J. Geophys. Res., 86, 7447-7450, https://doi.org/10.1029/JC086iC08p07447, 1981.

Grenfell, T. C. and Warren, S. G.: Representation of a nonspherical ice particle by a collection of independent spheres for scattering and absorption of radiation, J. Geophys. Res., 104, 3169731709, https://doi.org/10.1029/1999JD900496, 1999.

Grenfell, T. C., Light, B., and Perovich, D. K.: Spectral transmission and implications for the partitioning of shortwave radiation in arctic sea ice, Ann. Glaciol., 44, 1-6, https://doi.org/10.3189/172756406781811763, 2006.

He, C. and Flanner, M.: Snow Albedo and Radiative Transfer: Theory, Modeling, and Parameterization, in: Springer Series in Light Scattering, edited by A. Kokhanovsky, Springer International Publishing, Cham, 67-133, https://doi.org/10.1007/978-3030-38696-2_3, 2020.

He, C., Takano, Y., Liou, K.-N., Yang, P., Li, Q., and Chen, F.: Impact of Snow Grain Shape and Black Carbon-Snow 
Internal Mixing on Snow Optical Properties: Parameterizations for Climate Models, J. Climate, 30, 10019-10036, https://doi.org/10.1175/JCLI-D-17-0300.1, 2017.

Hoffman, M. J., Fountain, A. G., and Liston, G. E.: Nearsurface internal melting: a substantial mass loss on Antarctic Dry Valley glaciers, J. Glaciol., 60, 361-374, https://doi.org/10.3189/2014JoG13J095, 2014.

Holland, M. M., Bailey, D. A., Briegleb, B. P., Light, B., and Hunke, E.: Improved Sea Ice Shortwave Radiation Physics in CCSM4: The Impact of Melt Ponds and Aerosols on Arctic Sea Ice, J. Climate, 25, 1413-1430, https://doi.org/10.1175/JCLI-D-11$00078.1,2012$.

Järvinen, O. and Leppäranta, M.: Solar radiation transfer in the surface snow layer in Dronning Maud Land, Antarctica, Polar Science, 7, 1-17, https://doi.org/10.1016/j.polar.2013.03.002, 2013.

Joseph, J. H., Wiscombe, W. J., and Weinman, J. A.: The Delta-Eddington Approximation for Radiative Flux Transfer, J. Atmos. Sci., 33, 2452-2459, https://doi.org/10.1175/15200469(1976)033<2452:TDEAFR>2.0.CO;2, 1976.

King, M. D. and Simpson, W. R.: Extinction of UV radiation in Arctic snow at Alert, Canada $\left(82^{\circ} \mathrm{N}\right)$, J. Geophys. Res., 106, 12499 12507, https://doi.org/10.1029/2001JD900006, 2001.

Kokhanovsky, A. A. and Zege, E. P.: Scattering optics of snow, Appl. Opt., 43, 1589, https://doi.org/10.1364/AO.43.001589, 2004.

Kuipers Munneke, P., van den Broeke, M. R., Reijmer, C. H., Helsen, M. M., Boot, W., Schneebeli, M., and Steffen, K.: The role of radiation penetration in the energy budget of the snowpack at Summit, Greenland, The Cryosphere, 3, 155-165, https://doi.org/10.5194/tc-3-155-2009, 2009.

Leathers, R. A., Downes, T. V., Davis, C. O., and Mobley, C. D.: Monte Carlo Radiative Transfer Simulations for Ocean Optics: A Practical Guide, Memorandum, Naval Research Laboratory, Washington, DC, available at: https://www.oceanopticsbook.info/packages/iws_12h/ conversion/files/Leathersetal_NRL2004.pdf (last access: 11 October 2020), 2004.

Libois, Q., Picard, G., France, J. L., Arnaud, L., Dumont, M., Carmagnola, C. M., and King, M. D.: Influence of grain shape on light penetration in snow, The Cryosphere, 7, 1803-1818, https://doi.org/10.5194/tc-7-1803-2013, 2013.

Light, B., Maykut, G. A., and Grenfell, T. C.: A two-dimensional Monte Carlo model of radiative transfer in sea ice, J. Geophys. Res.-Oceans, 108, 3219, https://doi.org/10.1029/2002JC001513, 2003

Light, B., Maykut, G. A., and Grenfell, T. C.: A temperature-dependent, structural-optical model of first-year sea ice, J. Geophys. Res., 109, C06013, https://doi.org/10.1029/2003JC002164, 2004.

Light, B., Grenfell, T. C., and Perovich, D. K.: Transmission and absorption of solar radiation by Arctic sea ice during the melt season, J. Geophys. Res., 113, C03023, https://doi.org/10.1029/2006JC003977, 2008.

Liston, G. E. and Winther, J.-G.: Antarctic Surface and Subsurface Snow and Ice Melt Fluxes, J. Climate, 18, 1469-1481, https://doi.org/10.1175/JCLI3344.1, 2005.

Liston, G. E., Bruland, O., Elvehøy, H., and Sand, K.: Belowsurface ice melt on the coastal Antarctic ice sheet, J. Glaciology,
45, 273-285, https://doi.org/10.3189/002214399793377130, 1999a.

Liston, G. E., Bruland, O., Winther, J.-G., Elvehøy, H., and Sand, K.: Meltwater production in Antarctic blue-ice areas: sensitivity to changes in atmospheric forcing, Polar Res., 18, 283-290, https://doi.org/10.1111/j.1751-8369.1999.tb00305.x, 1999b.

Malinka, A., Zege, E., Heygster, G., and Istomina, L.: Reflective properties of white sea ice and snow, The Cryosphere, 10, 25412557, https://doi.org/10.5194/tc-10-2541-2016, 2016.

Malinka, A. V.: Light scattering in porous materials: Geometrical optics and stereological approach, J. Quant. Spectrosc. Ra., 141, 14-23, https://doi.org/10.1016/j.jqsrt.2014.02.022, 2014.

Markus, T., Neumann, T., Martino, A., Abdalati, W., Brunt, K., Csatho, B., Farrell, S., Fricker, H., Gardner, A., Harding, D., Jasinski, M., Kwok, R., Magruder, L., Lubin, D., Luthcke, S., Morison, J., Nelson, R., Neuenschwander, A., Palm, S., Popescu, S., Shum, C., Schutz, B. E., Smith, B., Yang, Y., and Zwally, J.: The Ice, Cloud, and land Elevation Satellite-2 (ICESat-2): Science requirements, concept, and implementation, Remote Sens. Environ., 190, 260-273, https://doi.org/10.1016/j.rse.2016.12.029, 2017.

Mätzler, C.: MATLAB Functions for Mie Scattering and Absorption, Version 2, Research Report, Institut für Angewandte Physik, Bern, Switzerland, https://doi.org/10.7892/boris.146550, 2002.

Maykut, G. A. and Untersteiner, N.: Some results from a timedependent thermodynamic model of sea ice, J. Geophys. Res., 76, 1550-1575, https://doi.org/10.1029/JC076i006p01550, 1971.

Meirold-Mautner, I. and Lehning, M.: Measurements and model calculations of the solar shortwave fluxes in snow on Summit, Greenland, Ann. Glaciol., 38, 279-284, https://doi.org/10.3189/172756404781814753, 2004.

Muhs, D. R.: The geologic records of dust in the Quaternary, Aeolian Res., 9, 3-48, https://doi.org/10.1016/j.aeolia.2012.08.001, 2013.

Mullen, P. C. and Warren, S. G.: Theory of the optical properties of lake ice, J. Geophys. Res., 93, 8403-8414, https://doi.org/10.1029/JD093iD07p08403, 1988.

Pegau, W. S. and Zaneveld, J. R. V.: Field measurements of in-ice radiance, Cold Reg. Sci. Technol., 31, 33-46, https://doi.org/10.1016/S0165-232X(00)00004-5, 2000.

Perovich, D. K.: The Optical Properties of Sea Ice., U.S. Army Cold Regions Research and Engineering Laboratory, Hanover, NH, https://apps.dtic.mil/dtic/tr/fulltext/u2/a310586.pdf, 1996.

Perovich, D. K. and Govoni, J. W.: Absorption coefficients of ice from 250 to $400 \mathrm{~nm}$, Geophys. Res. Lett., 18, 1233-1235, https://doi.org/10.1029/91GL01642, 1991.

Petit, J. R., Jouzel, J., Raynaud, D., Barkov, N. I., Barnola, J.M., Basile, I., Bender, M., Chappellaz, J., Davis, M., Delaygue, G., Delmotte, M., Kotlyakov, V. M., Legrand, M., Lipenkov, V. Y., Lorius, C., PÉpin, L., Ritz, C., Saltzman, E., and Stievenard, M.: Climate and atmospheric history of the past 420,000 years from the Vostok ice core, Antarctica, Nature, 399, 429_ 436, https://doi.org/10.1038/20859, 1999.

Petrenko, V. V., Severinghaus, J. P., Brook, E. J., Reeh, N., and Schaefer, H.: Gas records from the West Greenland ice margin covering the Last Glacial Termination: a horizontal ice core, Quatern. Sci. Rev., 25, 865-875, https://doi.org/10.1016/j.quascirev.2005.09.005, 2006. 
Picard, G., Libois, Q., and Arnaud, L.: Refinement of the ice absorption spectrum in the visible using radiance profile measurements in Antarctic snow, The Cryosphere, 10, 2655-2672, https://doi.org/10.5194/tc-10-2655-2016, 2016.

Price, P. B. and Bergström, L.: Enhanced Rayleigh scattering as a signature of nanoscale defects in highly transparent solids, Philos. Mag. A, 75, 1383-1390, https://doi.org/10.1080/01418619708209861, 1997a.

Price, P. B. and Bergström, L.: Optical properties of deep ice at the South Pole: scattering, Appl. Opt., 36, 4181-4194, https://doi.org/10.1364/AO.36.004181, 1997b.

Reeh, N., Oerter, H., and Thomsen, H. H.: Comparison between Greenland ice-margin and ice-core oxygen-18 records, Ann. Glaciol., 35, 136-144, https://doi.org/10.3189/172756402781817365, 2002.

Ridley, J. K. and Partington, K. C.: A model of satellite radar altimeter return from ice sheets, International J. Remote Sens., 9, 601-624, https://doi.org/10.1080/01431168808954881, 1988.

Rignot, E., Echelmeyer, K., and Krabill, W.: Penetration depth of interferometric synthetic-aperture radar signals in snow and ice, Geophys. Res. Lett., 28, 3501-3504, https://doi.org/10.1029/2000GL012484, 2001.

Ruth, U., Wagenbach, D., Steffensen, J. P., and Bigler, M.: Continuous record of microparticle concentration and size distribution in the central Greenland NGRIP ice core during the last glacial period, J. Geophys. Res.-Atmos., 108, 4098, https://doi.org/10.1029/2002JD002376, 2003.

Ryan, J. C., Hubbard, A. L., Stibal, M., Irvine-Fynn, T. D., Cook, J., Smith, L. C., Cameron, K., and Box, J. E.: Dark zone of the Greenland Ice Sheet controlled by distributed biologically-active impurities, Nat. Commun., 9, 1065, https://doi.org/10.1038/s41467-018-03353-2, 2018.

Schuster, A.: Radiation through a foggy atmosphere, Astrophys. J., 21, 1-22, 1905.

Schuster, C.: Weathering crust processes on melting glacier ice (Alberta, Canada), Theses and Dissertations (Comprehensive), no. 489, available at: http://scholars.wlu.ca/etd/489 (last access: 3 December 2016), 2001.

Schutz, B. E., Zwally, H. J., Shuman, C. A., Hancock, D., and DiMarzio, J. P.: Overview of the ICESat Mission, Geophys. Res. Lett., 32, L21S01, https://doi.org/10.1029/2005GL024009, 2005.

Smith, B. E., Gardner, A., Schneider, A., and Flanner, M.: Modeling biases in laser-altimetry measurements caused by scattering of green light in snow, Remote Sens. Environ., 215, 398-410, https://doi.org/10.1016/j.rse.2018.06.012, 2018.

Stibal, M., Box, J. E., Cameron, K. A., Langen, P. L., Yallop, M. L., Mottram, R. H., Khan, A. L., Molotch, N. P., Chrismas, N. A. M., Quaglia, F. C., Remias, D., Smeets, C. J. P. P., Broeke, M. R. van den, Ryan, J. C., Hubbard, A., Tranter, M., As, D., van and Ahlstrøm, A. P.: Algae Drive Enhanced Darkening of Bare Ice on the Greenland Ice Sheet, Geophys. Res. Lett., 44, 11463-11471, https://doi.org/10.1002/2017GL075958, 2017.

Takeuchi, N.: Optical characteristics of cryoconite (surface dust) on glaciers: the relationship between light absorbency and the property of organic matter contained in the cryoconite, Ann. Glaciol., 34, 409-414, https://doi.org/10.3189/172756402781817743, 2002.
Taylor, B. N. and Kuyatt, C. E.: Guidelines for Evaluating and Expressing the Uncertainty of NIST Measurement Results (NIST Technical Note vol. 1297), National Institue of Standards and Technology, Gaithersburg, MD, http://physics.nist.gov/Pubs/ guidelines/TN1297/tn1297s.pdf (last access: 18 January 2021), 1994.

Tuzet, F., Dumont, M., Arnaud, L., Voisin, D., Lamare, M., Larue, F., Revuelto, J., and Picard, G.: Influence of light-absorbing particles on snow spectral irradiance profiles, The Cryosphere, 13, 2169-2187, https://doi.org/10.5194/tc-13-2169-2019, 2019.

van de Hulst, H. C.: Multiple light scattering: tables, formulas, and applications, Academic Press, New York, 1980.

van den Broeke, M., Smeets, P., Ettema, J., van der Veen, C., van de Wal, R., and Oerlemans, J.: Partitioning of melt energy and meltwater fluxes in the ablation zone of the west Greenland ice sheet, The Cryosphere, 2, 179-189, https://doi.org/10.5194/tc-2179-2008, 2008.

Wang, L., Jacques, S. L., and Zheng, L.: MCML - Monte Carlo modeling of light transport in multi-layered tissues, Comput. Meth. Prog. Bio., 47, 131-146, https://doi.org/10.1016/01692607(95)01640-F, 1995.

Warren, S. G.: Optical properties of snow, Rev. Geophys., 20, 6789, https://doi.org/10.1029/RG020i001p00067, 1982.

Warren, S. G.: Optical constants of ice from the ultraviolet to the microwave, Appl. Opt., 23, 1206-1225, https://doi.org/10.1364/AO.23.001206, 1984.

Warren, S. G. and Brandt, R. E.: Optical constants of ice from the ultraviolet to the microwave: A revised compilation, J. Geophys. Res., 113, D14220, https://doi.org/10.1029/2007JD009744, 2008.

Warren, S. G., Brandt, R. E., Grenfell, T. C., and McKay, C. P.: Snowball Earth: Ice thickness on the tropical ocean, J. Geophys. Res.-Oceans, 107, 31-1-31-18, https://doi.org/10.1029/2001JC001123, 2002.

Warren, S. G., Brandt, R. E., and Grenfell, T. C.: Visible and near-ultraviolet absorption spectrum of ice from transmission of solar radiation into snow, Appl. Opt., 45, 5320-5334, https://doi.org/10.1364/AO.45.005320, 2006.

Wientjes, I. G. M., Van de Wal, R. S. W., Reichart, G. J., Sluijs, A., and Oerlemans, J.: Dust from the dark region in the western ablation zone of the Greenland ice sheet, The Cryosphere, 5, 589-601, https://doi.org/10.5194/tc-5-589-2011, 2011.

Wientjes, I. G. M., De Van Wal, R. S. W., Schwikowski, M., Zapf, A., Fahrni, S., and Wacker, L.: Carbonaceous particles reveal that Late Holocene dust causes the dark region in the western ablation zone of the Greenland ice sheet, J. Glaciol., 58, 787-794, https://doi.org/10.3189/2012JoG11J165, 2012.

Wiscombe, W. J. and Warren, S. G.: A Model for the Spectral Albedo of Snow. I: Pure Snow, J. Atmos. Sci., $\quad 37, \quad 2712-2733$, https://doi.org/10.1175/15200469(1980)037<2712:AMFTSA>2.0.CO;2, 1980.

Woschnagg, K. and Price, P. B.: Temperature dependence of absorption in ice at $532 \mathrm{~nm}$, Appl. Opt., 40, 2496-2500, https://doi.org/10.1364/AO.40.002496, 2001.

Yallop, M. L., Anesio, A. M., Perkins, R. G., Cook, J., Telling, J., Fagan, D., MacFarlane, J., Stibal, M., Barker, G., Bellas, C., Hodson, A., Tranter, M., Wadham, J., and Roberts, N. W.: Photophysiology and albedo-changing potential of the ice algal com- 
munity on the surface of the Greenland ice sheet, ISME J., 6 , 2302-2313, https://doi.org/10.1038/ismej.2012.107, 2012.

Yang, Y., Marshak, A., Han, M., Palm, S. P., and Harding, D. J.: Snow grain size retrieval over the polar ice sheets with the Ice, Cloud, and land Elevation Satellite (ICESat) observations, J. Quant. Spectrosc. Ra., 188, 159-164, https://doi.org/10.1016/j.jqsrt.2016.03.033, 2017.

York, D., Evensen, N. M., Martınez, M. L., and De Basabe Delgado, J.: Unified equations for the slope, intercept, and standard errors of the best straight line, Am. J. Phys., 72, 367-375, https://doi.org/10.1119/1.1632486, 2004.

Zebker, H. A. and Weber Hoen, E.: Penetration depths inferred from interferometric volume decorrelation observed over the Greenland Ice Sheet, IEEE T. Geosci. Remote Sens., 38, 2571-2583, https://doi.org/10.1109/36.885204, 2000.
Zhang, X., Qiu, J., Li, X., Zhao, J., and Liu, L.: Complex refractive indices measurements of polymers in visible and near-infrared bands, Appl. Opt., 59, 2337, https://doi.org/10.1364/AO.383831, 2020.

Zieger, P., Weingartner, E., Henzing, J., Moerman, M., de Leeuw, G., Mikkilä, J., Ehn, M., Petäjä, T., Clémer, K., van Roozendael, M., Yilmaz, S., Frieß, U., Irie, H., Wagner, T., Shaiganfar, R., Beirle, S., Apituley, A., Wilson, K., and Baltensperger, U.: Comparison of ambient aerosol extinction coefficients obtained from in-situ, MAX-DOAS and LIDAR measurements at Cabauw, Atmos. Chem. Phys., 11, 2603-2624, https://doi.org/10.5194/acp11-2603-2011, 2011. 